\title{
A scalable and highly immunogenic virus-like particle-based vaccine against SARS-CoV-2
}

\author{
Mona O. Mohsen ${ }^{1,2,3}$ | Ina Balke ${ }^{4}$ ( ) Simon Zinkhan ${ }^{1,2}$ (1) | Villija Zeltina ${ }^{4}$ | \\ Xuelan Liu ${ }^{1,2,5}$ | Xinyue Chang ${ }^{1,2}$ (-) Pascal S. Krenger ${ }^{1,2}$ | Kevin Plattner ${ }^{1,2}$ | \\ Zahra Gharailoo $^{1,2}$ | Anne-Cathrine S. Vogt ${ }^{1,2}$ | Gilles Augusto ${ }^{1,2,6}$ | \\ Marianne Zwicker $^{1,2}$ | Salony Roongta ${ }^{1,2}$ | Dominik A. Rothen ${ }^{1,2}$ | Romano Josi ${ }^{1,2}$ | \\ Joana J. da Costa ${ }^{1,2}$ | Jan M. Sobczak ${ }^{1,2}$ | Aleksandra Nonic ${ }^{1,2}$ | Lee-Anne Brand ${ }^{1,2}$ | \\ Katja Nuss $^{7}$ | Byron Martina ${ }^{8,9}$ | Daniel E. Speiser ${ }^{1,2}$ | Thomas Kündig ${ }^{10}$ | \\ Gary T. Jennings ${ }^{3}$ | Senta M. Walton ${ }^{3}$ | Monique Vogel ${ }^{1,2}{ }^{\infty}$ | Andris Zeltins ${ }^{4}$ | \\ Martin F. Bachmann ${ }^{1,2}$ ()
}

\footnotetext{
${ }^{1}$ Department of Rheumatology and Immunology, University Hospital, Bern, Switzerland

${ }^{2}$ Department of BioMedical Research, University of Bern, Bern, Switzerland

${ }^{3}$ Saiba AG, Pfaeffikon, Switzerland

${ }^{4}$ Latvian Biomedical Research \& Study Centre, Riga, Latvia

${ }^{5}$ International Immunology Center, Anhui Agricultural University, Hefei, China

${ }^{6}$ Nuffield Department of Medicine, Centre for Cellular and Molecular Physiology (CCMP), The Jenner Institute, University of Oxford, Oxford, UK

${ }^{7}$ Musculoskeletal Research Unit (MSRU), Department of Molecular Mechanisms of Disease (DMMD), Vetsuisse Faculty, University of Zurich (UZH), Zurich, Switzerland

${ }^{8}$ Erasmus Medical Center, department of Viroscience, Rotterdam, The Netherlands

${ }^{9}$ Artemis Bio-Support, Delft, The Netherlands

${ }^{10}$ Department of Dermatology, University Hospital Zurich (USZ), University of Zurich (UZH), Zurich, Switzerland
}

Correspondence

Mona Mohsen, Department of

Rheumatology and Immunology,

University Hospital, Bern, 3010 Bern,

\begin{abstract}
Background: SARS-CoV-2 caused one of the most devastating pandemics in the recent history of mankind. Due to various countermeasures, including lock-downs, wearing masks, and increased hygiene, the virus has been controlled in some parts of the world. More recently, the availability of vaccines, based on RNA or adenoviruses, has greatly added to our ability to keep the virus at bay; again, however, in some parts of the world only. While available vaccines are effective, it would be desirable to also have more classical vaccines at hand for the future. Key feature of vaccines for longterm control of SARS-CoV-2 would be inexpensive production at large scale, ability to make multiple booster injections, and long-term stability at $4^{\circ} \mathrm{C}$.

Methods: Here, we describe such a vaccine candidate, consisting of the SARS-CoV-2 receptor-binding motif (RBM) grafted genetically onto the surface of the immunologically optimized cucumber mosaic virus, called $\mathrm{CuMV}_{\mathrm{TT}}-\mathrm{RBM}$.

Results: Using bacterial fermentation and continuous flow centrifugation for purification, the yield of the production process is estimated to be $>2.5$ million doses per 1000-litre fermenter run. We demonstrate that the candidate vaccine is highly immunogenic in mice and rabbits and induces more high avidity antibodies compared to convalescent human sera. The induced antibodies are more cross-reactive to mutant RBDs of variants of concern ( $\mathrm{VoC}$ ). Furthermore, antibody responses are neutralizing and long-lived. In addition, the vaccine candidate was stable for at least 14 months at $4^{\circ} \mathrm{C}$.
\end{abstract}


Switzerland.

Email: mona.mohsen@dbmr.unibe.ch

Funding information

This work was supported by Saiba AG and Inselspital Bern.
Conclusion: Thus, the here presented VLP-based vaccine may be a good candidate for use as conventional vaccine in the long term.

KEYWORDS

COVID-19, SARS-CoV-2, vaccine, virus-like particles

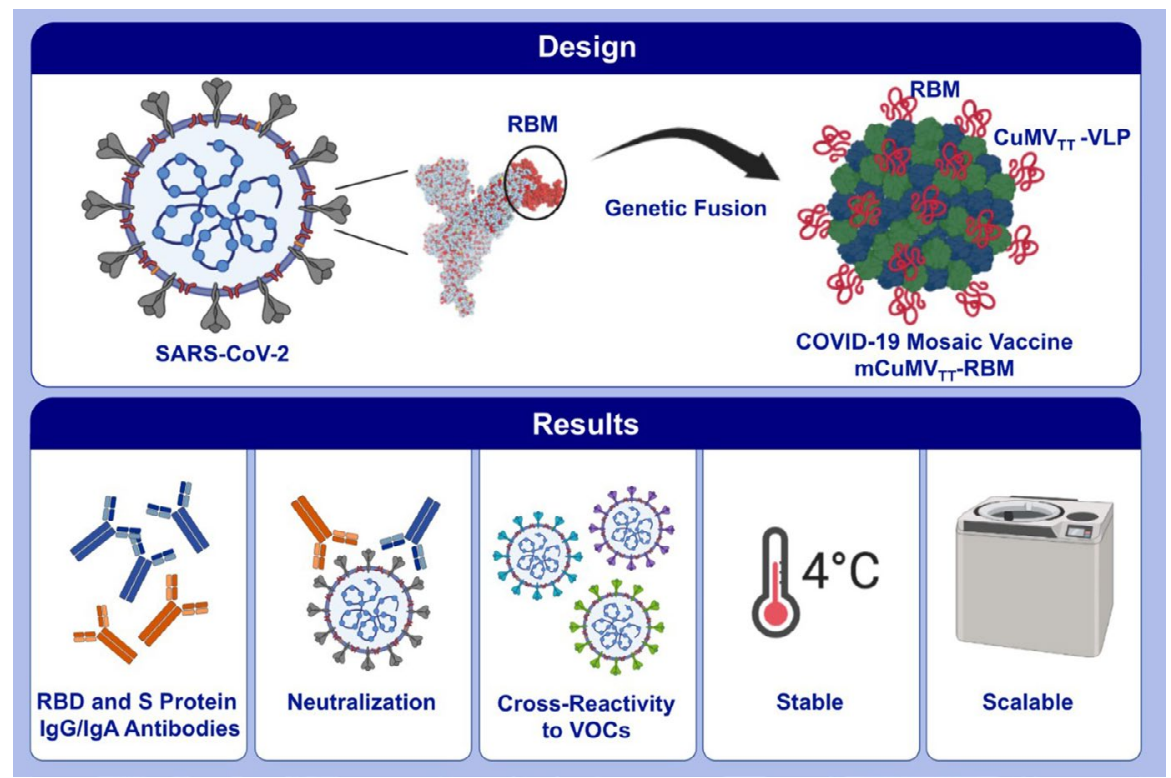

\section{GRAPHICAL ABSTRACT}

In this study, we describe a novel conventional COVID-19 vaccine that consists of the RBM of SARS-CoV-2 genetically grafted onto the surface of our optimized cucumber-mosaic virus-like particles. We demonstrate that the vaccine candidate $\left(\mathrm{mCuMV}_{\mathrm{TT}} \mathrm{RBM}^{\mathrm{RB}}\right.$ ) is highly immunogenic in mice and rabbits, can efficiently neutralize SARS-CoV-2, and is stable and highly scalable. The induced antibodies show cross-reactivity with VoC.

Abbreviations: COVID-19, coronavirus disease 2019; CuMV $\mathrm{TT}^{-V L P s}$, cucumber-mosaic virus-like particles; RBD, receptor-binding domain; RBM, receptor-binding motif; SARS-CoV-2, severe acute respiratory syndrome coronavirus 2; VOCs, variant of concerns

\section{1 | INTRODUCTION}

Since the outbreak of the global pandemic caused by SARS-CoV-2, WHO has reported 170 million confirmed cases by 3 June 2021 including $\sim 3.5$ million deaths (WHO, 3 June 2021). The pandemic has put a heavy toll on public health systems and world's economy. To limit the damage, efforts have been directed toward vaccine development. On 12th May 2021 around one billion doses of different vaccines have been administered worldwide (WHO, 12th May 2021). Although SARS-CoV-2 causes mostly mild symptoms such as coughing, fever and breathlessness, symptoms may become much more severe, in particular in elderly people and people with chronic diseases which may develop to severe pneumonia and other symptoms including organ failure and death. ${ }^{1,2}$ SARS-CoV-2 has a lower fatality rate (2.3\%) in comparison with SARS (9.5\%) and MERS (34.4\%). ${ }^{3}$ However, it transmits much more readily, mostly because non-symptomatic and pre-symptomatic individuals can spread the virus. Thus, while MERS-CoV and SARS-CoV outbreaks have been sporadic and geographically restricted, SARS-CoV-2 has rapidly spread around the world ${ }^{4,5}$.

The positive-sense ssRNA SARS-CoV-2 virus has a genome of about 29,700 nucleotides with $79.5 \%$ identity to SARS-CoV-1. Its genome encodes four main structural proteins; spike protein, membrane protein, nucleocapsid protein, and the envelope protein ${ }^{6,7}$. SARS-CoV-2 binds to angiotensin-converting enzyme 2 (ACE2) via the (receptor-binding domain) RBD of its spike protein that protrudes from the viral envelope. Interaction of RBD with ACE2 is the first step in a cascade of events leading to viral entry and ultimately replication ${ }^{8}$. Neutralizing antibodies against SARS-CoV-2 are mostly targeting the RBD of the spike protein. Within RBD, the receptorbinding motif (RBM) is of particular importance as it directly interacts with ACE2 ${ }^{9}$. Interestingly, RBM shows no glycosylation or other post-translational modifications and therefore is well suited for production in bacterial expression systems ${ }^{11}$.

Vaccines are the most reliable, cost-effective, and efficient strategy to prevent infectious diseases. Vaccine candidates must induce 
sufficient quantities of high-affinity antibodies to neutralize the invading virus. Since the initiation of the pandemic, a full spectrum of vaccine types has been tested in preclinical and clinical trials. Vaccine platforms employed mRNA, DNA, viral vectors, inactivated or live-attenuated virus ${ }^{10,12}$, and recombinant proteins. The full length of spike protein, RBD, S1 subunit, fusion peptide (FP), and the $\mathrm{N}$-terminal domain (NTD) of the spike protein have been targeted by vaccines that are licensed or undergoing development ${ }^{4,13}$.

Virus-like particles (VLPs) represent one of the conventional vaccine platforms in the sense that there are globally marketed VLPbased products, for example, hepatitis B virus (HBV) and human papilloma virus (HPV) vaccines have demonstrated the clinical usefulness of this modality. VLPs consist of viral structural proteins that upon recombinant expression, self-assemble into icosahedral or rarely helical particles ${ }^{14}$. Recently, we have developed an immunologically optimized VLP platform based on the cucumber mosaic virus $\left(\mathrm{CuMV}_{\mathrm{TT}}-\mathrm{VLPS}\right)^{15}$. $\mathrm{CuMV}_{\mathrm{TT}}$-VLPs incorporate a universal T-cell epitope derived from tetanus toxin (TT) ${ }^{16}$. The newly developed platform enhances the interaction between $T$ helper $\left(T_{H}\right)$ cells and $B$ cells, and is expected to improve responses in elderly individuals who are often less reactive to vaccines. This is supported by the fact that pre-existing immunity to the chosen TT epitope is very broad in humans (and animals) as the peptide binds to essentially all HLA-DR molecules and most people have been immunized many times against TT. In addition, $\mathrm{CuMV}_{\mathrm{TT}}$-VLPs are packaged with bacterial RNA which is a ligand for toll-like receptor (TLR) 7 and 8 and serves as a potent natural adjuvant ${ }^{16,17}$. By displaying antigens on $\mathrm{CuMV}_{\mathrm{TT}}-\mathrm{VLPs}$, it was possible to induce high levels of antigen-specific antibodies in mice, rats, cats, dogs, and horses and treat diseases such as atopic dermatitis in dogs or insect bite hypersensitivity in horses ${ }^{18,19}$.

In the current study, we have designed and developed a scalable and immunogenic VLP-based COVID-19 vaccine by genetically fusing the RBM of the spike protein from SARS-CoV-2 into $\mathrm{CuMV}_{\mathrm{TT}}-\mathrm{VLPS}$. The data show that this vaccine is highly immunogenic and capable of inducing both RBD-specific IgG and IgA antibodies as well as a strong viral neutralizing antibody response. Furthermore, the vaccine production process is highly scalable, potentially allowing the production of millions of doses in a single $1000 \mathrm{~L}$ bacterial fermenter run.

\section{MATERIALS AND METHODS}

\section{1 | Mosaic CuMV $\mathrm{TT}_{\mathrm{TT}}$-RBM vaccine production, purification, and analysis}

For expression and purification of mosaic $\mathrm{CuMV}_{\mathrm{TT}}-\mathrm{RBM}^{\mathrm{m}} \mathrm{m} \mathrm{CuMV}_{\mathrm{TT}^{-}}$ RBM), E. coli C2566 (New England Biolabs, USA) competent cells were transformed with the plasmid pETDu-CMVB3d-nCoV-M-CMV (construction details are summarized in Supplementary data 1).

After selection of clones with the highest expression level of target proteins, E. coli culture was grown in $100 \mathrm{ml}$ of $2 \mathrm{TY}$ medium ( $1.6 \%$ trypton, $1 \%$ yeast extract, $0.5 \% \mathrm{NaCl}, 0.1 \%$ glucose) containing ampicillin $(100 \mathrm{mg} / \mathrm{I})$ on an orbital shaker at $30^{\circ} \mathrm{C}$ to the $\mathrm{OD}_{600}$ value of 0.8-1.0. Then, the cells were induced with 0.2mM IPTG, and the medium was supplemented with $5 \mathrm{mM} \mathrm{MgCl}_{2}$. Incubation was continued on the rotary shaker $\left(200 \mathrm{rpm}, 20^{\circ} \mathrm{C}, 18 \mathrm{~h}\right)$. The resulting biomass was collected by low-speed centrifugation and was frozen at $-20^{\circ} \mathrm{C}$. To disrupt the cells, the biomass was resuspended $10 \mathrm{ml}$ of buffer (20mM Tris, 5mM EDTA, 5mM Et-SH, 5\% glycerol, 10\% sucrose, $\mathrm{pH}$ 8.0) and further treated with ultrasound (Hielscher 200 , power $70 \%$, pulse $50 \%, 16 \mathrm{~min}$ ) on ice. Then, $0.5 \%$ Triton $\mathrm{X}-100$ was added and the solution was rotated at $10 \mathrm{rpm} \mathrm{ON}$ at $4^{\circ} \mathrm{C}$ without centrifugation. The solution was then clarified for $10 \mathrm{~min}$ at 10000 rpm (rotor: F-346-38 Eppendorf), and the pellet was discarded. The soluble fraction was loaded on the top of the sucrose gradient (20-60\%; in buffer containing 20mM Tris, 2mM EDTA, 5\% glycerol, 0.5\% TX-100, pH 8.0) and centrifugated in Beckman SW32 rotor for $6 \mathrm{~h}$ at $25500 \mathrm{rpm}$ at $18^{\circ} \mathrm{C}$. The gradient fractions ${ }^{6 m}$ were then removed from the bottom of the $38 \mathrm{ml}$ tube. The CUMV VLP containing fraction (40 and $50 \%$ sucrose, pooled) was diluted 1:1 with buffer (20mM Tris, $2 \mathrm{mM}$ EDTA, $5 \%$ glycerol, $\mathrm{pH}$ 8.0). The VLPs were sedimented using Type 70 rotor (Beckman, $50000 \mathrm{rpm}, 4 \mathrm{~h}, 4^{\circ} \mathrm{C}$ ). Then, the pellet was dissolved $\mathrm{ON}$ in $4 \mathrm{ml}$ of $20 \mathrm{mM}$ Tris, $2 \mathrm{mM}$ EDTA at $4^{\circ} \mathrm{C}$. The solution was clarified by centrifugation ( $5 \mathrm{~min}, 14000 \mathrm{rpm}$ ), the clarified solution overlaid on top of the $30 \%$ sucrose "cushion" solution in 20mM Tris, 2mM EDTA, 0.5\% TX-100, pH 8.0 The VLPs were sedimented using Beckman TLA100.3 rotor (72000 rpm, $60 \mathrm{~min}, 4^{\circ} \mathrm{C}$ ). The pellet was solubilized in $2 \mathrm{ml}$ of $20 \mathrm{mM}$ Tris, $2 \mathrm{mM}$ EDTA, and clarified again by centrifugation (5min, 14000 rpm). Endotoxin measurement in the produced vaccine showed $\sim 50 \mathrm{EU} / \mathrm{mg}$. $\mathrm{mCuMV}_{\mathrm{TT}^{-}}$ RBM vaccine candidate was next characterized using SDS-PAGE, agarose gel, electron microscopy, and dynamic light scattering (DLS). Protein concentration was determined using BCA test.

\subsection{Dynamic light scattering (DLS)}

Sample VLP solution ( $1 \mathrm{mg} / \mathrm{ml}$ ) was analyzed on a Zetasizer Nano ZS instrument (Malvern Instruments Ltd, UK). The results of three measurements were analyzed by DTS software (Malvern, version 6.32). ${ }^{16}$

\section{3 | Electron microscopy}

Physical stability and integrity of the mosaic $\mathrm{CuMV}_{\mathrm{TT}}-\mathrm{RBM}$ were visualized by transmission electron microscopy (Philips CM12 EM). For imaging, sample grids were glow discharged and $2 \mu$ of purified $\mathrm{CuMV}_{\mathrm{TT}}-\mathrm{RBM}(3 \mathrm{mg} / \mathrm{ml})$ was added for 30 s. Grids were washed $3 \mathrm{x}$ with $\mathrm{ddH}_{2} \mathrm{O}$ and negatively stained with $5 \mu$ of $5 \%$ uranyl acetate for 30s. Excess uranyl acetate was removed by pipetting and the grids were air dried for 10min. Images were taken with $84,000 \mathrm{X}$ and 110,000X magnification.

\section{4 | Binding ELISA assay}

To test if the vaccine can bind the relevant human receptor ACE2, the plates were coated with $1 \mu \mathrm{g} / \mathrm{ml}$ of ACE2 in PBS at a volume of 
$50 \mu \mathrm{l} /$ well. The plate was incubated at $4^{\circ} \mathrm{C}$ overnight. The plate was washed with PBS, Tween $0.01 \%$. Added $50 \mu \mathrm{l} /$ well of Superblock solution (Thermo Fisher, 37518) and incubated for $1 \mathrm{~h}$ at RT on a shaker. The blocking solution was flicked off, and $50 \mu$ l of the $\mathrm{CuMV}_{\mathrm{TT}}-\mathrm{RBM}$ or $\mathrm{CuMV}_{\mathrm{TT}}-\mathrm{VLPs}$ at $1 \mu \mathrm{g} / \mathrm{ml}$ was added to the first row of the plate followed by 1:3 dilution. The plate was incubated for $1 \mathrm{~h}$ at RT, washed with PBS+Tween $0.01 \%$. 50 $\mu$ l of mouse anti-CuMV $\mathrm{TT}_{\mathrm{TT}}$ monoclonal antibody (clone 1-1A8/ batch 2 ) at a concentration of $1 \mu \mathrm{g} / \mathrm{ml}$ was added to each well as a secondary antibody and incubated for $1 \mathrm{~h}$ at RT on a shaker. The plate was washed and $50 \mu \mathrm{l}$ of the detection antibody; HRP labeled goat anti-mouse IgG Fc gamma at a dilution of 1:1000 in PBS-Casein $0.15 \%$ was added to each well. The plate was incubated for $1 \mathrm{~h}$ at $\mathrm{RT}$. The plate was developed, and $\mathrm{OD}_{450}$ reading was performed (BioTek, USA).

\section{5 | Mice}

In vivo experiments were performed using 8- to 12-week-old female, BALB/cOlaHsd wild-type (wt) mice purchased from Harlan (Netherlands). All animal procedures were conducted in accordance with the Swiss Animal Act (455.109.1 - 5 September 2008) of University of Bern. All animals were treated for experimentation according to protocols approved by the Swiss Federal Veterinary Office.

\section{6 | Rabbits}

A toxicology study was performed in rabbits according to $\mathrm{ICH}$ guidelines for the preclinical safety evaluation of vaccines and the preclinical pharmacological and toxicological testing of vaccines. Studies were performed according to the principles of good laboratory practice at the Musculoskeletal Research Unit (MSRU) of the Vetsuisse Faculty of the University of Zürich.

\section{7 | Human sera}

Human sera were obtained from 5 different COVID-19 convalescent patients which were recruited at the University Hospital of Bern, Bern, Switzerland as described ${ }^{20}$. Participants were recruited via three different routes: (a) inpatients with a SARS-CoV-2 test result (real-time PCR; RT-PCR), (b) medical personnel of the Inselspital, and (c) residual material from patients stored at the Liquid Biobank Bern (www.biobankbern.ch). Inclusion criteria of inpatients are as follows: (a) hospitalization in Inselspital, (b) tested positive for SARS-CoV-2 using RT-PCR (nasopharyngeal swab), (c) aged 18 or older, and (d) signed general consent.

\section{8 | Vaccination regimen/dose/sera collection}

Wild-type BALB/cOlaHsd mice were vaccinated subcutaneously (s.c.) using different regimens and doses as summarized in Table 1. After comparing the efficacy of the different regimens and doses, $100 \mu \mathrm{g}$ of the vaccine or a control ( $\mathrm{CuMV}_{\mathrm{TT}}-\mathrm{VLPs}$, do not display an epitope) was used in the experiments shown in this study. The regimens used in this study are as follows: D0/D14 (Prime/Boost), D0/D28 (Prime/Boost), and D0/D14/D42 (Prime $/ 1^{\text {st }}$ Boost $/ 2^{\text {nd }}$ Boost). mCuMV $\mathrm{TT}^{-}$RBM candidate vaccine was diluted in $20 \mathrm{mM}$ Tris, $2 \mathrm{mM}$ EDTA in a final volume of $100 \mu$ l for final injection. Serum was collected on a weekly basis.

\subsection{Expression and purification of RBD mutants}

SARS-CoV-2 RBD wildtype, $_{\text {RBD }} \mathrm{K} 417 \mathrm{~N}, \quad \mathrm{RBD}_{\mathrm{E} 484 \mathrm{~K}}, \mathrm{RBD}_{\mathrm{N} 501 \mathrm{Y}}$, $\mathrm{RBD}_{\mathrm{K} 417 \mathrm{~N} / \mathrm{E} 484 \mathrm{~K} / \mathrm{N} 501 \mathrm{Y}}$, and $\mathrm{RBD}_{\mathrm{L}_{452 R / E 484 Q}}$ were cloned as a synthetic gene into PTWIST-CMV-BetaGlobin-WPRE-Neo vector (Twist Biosciences, CA, USA) and expressed in HEK293F cells through the Expi293 system (Thermo Fisher Scientific, MA, USA). Purification was performed by IMAC using a HiTrap TALON crude column (Cytiva, Uppsala, Sweden).

\subsection{Enzyme-linked immunosorbant assay (ELISA)}

To determine the total IgG antibodies against the candidate vaccine $\mathrm{mCuMV}_{\mathrm{TT}}-\mathrm{RBM}$ in sera of vaccinated mice, ELISA plates were

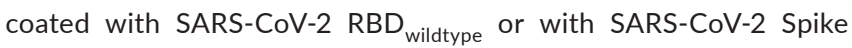
(Sinobiological, Beijing, China) at concentrations of either $1 \mu \mathrm{g} / \mathrm{ml}$ overnight. ELISA plates were washed with PBS-0.01\% Tween and blocked using $100 \mu$ PBS-Casein $0.15 \%$ for $2 \mathrm{~h}$ in RT. Sera from vaccinated mice serially diluted 1:3 starting with a dilution of 1:20 and incubated for $1 \mathrm{~h}$ at RT. After washing with PBS-0.01\%Tween, goat anti-mouse IgG conjugated to horseradish peroxidase (HRP) (Jackson ImmunoResearch, West Grove, Pennsylvania) was added at 1/2000

\begin{tabular}{|ll}
\hline Dose & Vaccination Regimen \\
\hline $5 \mu \mathrm{g}$ prime $/ 5 \mu \mathrm{g}$ boost & D0/D14 \\
\hline $20 \mu \mathrm{g}$ prime $/ 20 \mu \mathrm{g}$ boost & D0/D7/D14 \\
& D0/D14 \\
& D0/D28 \\
\hline $100 \mu \mathrm{g}$ prime $/ 100 \mu \mathrm{g}$ boost & D0/D14 \\
& D0/D28 \\
\hline $100 \mu \mathrm{g}$ prime $/ 100 \mu \mathrm{g} 1^{\text {st }}$ boost $/ 100 \mu \mathrm{g} 2^{\text {nd }}$ boost & D0/D28/D42 \\
\hline
\end{tabular}

TABLE 1 Tested doses and vaccination regimens 
and incubated for $1 \mathrm{~h}$ at RT ELISA was developed with tetramethylbenzidine (TMB), stopped by adding equal $1 \mathrm{M} \mathrm{H} 2 \mathrm{SO} 4$ solution, and read at $\mathrm{OD}_{450} \mathrm{~nm}$ or expressed as $\log _{10} \mathrm{OD}_{50}$. Detecting RBDspecific IgGs against mutated RBDs was carried out in a similar way.

IgG subclasses were measured from sera collected on day 42 following the same described ELISA protocol. The following secondary antibodies were used: goat anti-mouse IgG1-HRP and goat antimouse IgG2a-HRP (1:1000) (Thermo Fischer Scientific, Waltham, Massachusetts), goat anti-mouse IgG2b-HRP (SouthernBiotech, Birmingham, Alabama) 1:4000, rat anti-mouse IgG3-HRP (Becton, Dickinson, Franklin Lakes, New Jersey) 1:2000.

To detect IgA antibodies, the plates were coated with $1 \mu \mathrm{g} / \mathrm{ml}$ SARS-CoV-2 RBDwildtype protein and goat anti-mouse IgA POX (ICN 55549, ID 91, 1:1000 dilution) as the secondary antibody was used. An additional step prior to serum incubation was added in order to deplete IgG. $10 \mu$ l of protein G beads (Invitrogen, USA) were transferred into a tube and placed into a magnet. The liquid was removed and the $75.6 \mu \mathrm{l}$ diluted sera in PBS-Casein $0.15 \%$ was added to the beads and mixed. The tube was incubated on a rotator at RT for 10 minutes. The tubes were placed back into the magnet, and ELISA was carried out as described above. Analysis and graphs were created using GraphPad PRISM 9, version 9.1.0 (216), 15 March 2021.

To determine RBD-specific IgG antibodies against the candidate vaccine $\mathrm{mCuMV}_{\mathrm{TT}}-\mathrm{RBM}$ in sera of vaccinated rabbits, ELISA plates

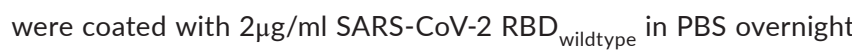
at $+4^{\circ} \mathrm{C}$. ELISA plates were washed 4 times with PBST (1x PBS / $0.05 \%(v / v)$ Tween 20), and plates were blocked with $200 \mu \mathrm{L} /$ well Blocking buffer (ThermoFisher, Life Technologies Europe BV, Zug Switzerland). Plates were incubated at $+22^{\circ} \mathrm{C}$ between 2 and $4 \mathrm{~h}$. After removal of the blocking buffer and a washing step, diluted internal standard $(1 \mu \mathrm{g} / \mathrm{mL})$ and the pre-diluted immune sera (1:50) were added to the wells of the first column on the ELISA plate (150 $\mu \mathrm{L} /$ well). The internal standard and the immune sera were then serially threefold diluted in dilution buffer ( $2 \%$ BSA/ PBST). Plates were incubated for $2 \mathrm{~h}$ at $+22^{\circ} \mathrm{C}$ and washed. $100 \mu \mathrm{L} /$ well of detection antibody (1:10'000 diluted in dilution buffer, Peroxidase-conjugated polyclonal goat anti-rabbit IgG $(\mathrm{H}+\mathrm{L})$ (Jackson Immuno Research, cat no 111-035-144) was added and incubated for $2 \mathrm{~h}$ at $+22^{\circ} \mathrm{C}$. After rigorous washing, $100 \mu \mathrm{l} /$ well of the OPD detection solution (POD tablets (Sigma cat. no. P6912), phosphate citrate tablets (Sigma cat. no. P4809), $30 \% \mathrm{H}_{2} \mathrm{O} 2$ (Sigma cat. No. 1009)) was added and reaction was stopped by addition of $50 \mu \mathrm{L} /$ well $2 \mathrm{M} \mathrm{H}_{2} \mathrm{SO}_{4}$. Absorption at $490 \mathrm{~nm}$ was quantified in each well using the plate reader Spark $10 \mathrm{M}$ (Tecan).

\subsection{1 | Avidity (ELISA)}

To test IgG antibody avidity against SARS-CoV-2 full spike protein and RBD protein, threefold serial dilutions of $1 / 20$ diluted mice sera, were added to duplicate ELISA plates coated over night with $1 \mu \mathrm{g} / \mathrm{ml}$ RBD or spike protein. After incubation at RT for $1 \mathrm{~h}$, the plates were washed once in PBS-0.01\% Tween, and then washed $3 x$ with $7 \mathrm{M}$ urea in PBS-0.05\%Tween or with PBS-0.05\% Tween for 5 min every time. After washing with PBS-0.05\%Tween, goat anti-mouse IgG conjugated to horseradish peroxidase (HRP) (Jackson ImmunoResearch, West Grove, Pennsylvania) was added 1/2000 and incubated for $1 \mathrm{~h}$ at RT. Plates were developed and read at $\mathrm{OD}_{450}$.

\subsection{2 | Cytopathic effect-based neutralization assay (CPE)}

To determine the neutralizing ability and capacity of vaccine-induced antibodies, a CPE assay was performed using wildtype SARS-CoV-2 (SARS-CoV-2/ABS/NL20). Serum samples were heat-inactivated for $30 \mathrm{~min}$ at $56^{\circ} \mathrm{C}$. Two fold serial dilutions were prepared starting at 1:20 up to $1: 160.100 \mathrm{TCID}_{50}$ of the virus was added to each well and incubated for $37^{\circ} \mathrm{C}$ for $1 \mathrm{~h}$. The mixture has been added on a monolayer of Vero cells and incubated again for $37^{\circ} \mathrm{C}$ for 4 days. Four days later, the cells were inspected for cytopathic effect. The titer was expressed as the highest dilution that fully inhibits formation of CPE.

\subsection{3 | Statistical analysis}

Data were analyzed and presented as (mean \pm SEM) using Student's $t$ test, one-way ANOVA or Area Under Curve (AUC) as mentioned in the figure legend, with GraphPad PRISM 9. The value of $p<0.05$ was considered statistically significant $\left({ }^{*} p<0.01,{ }^{* *} p<0.001,{ }^{* * *} p<0.0001\right)$.

\subsection{4 | Continuous flow centrifugation}

Bacterial lysates were generated as described in 2.1 and applied to a sucrose gradient in a continuous flow centrifugation (AW Promatix $1000^{\mathrm{TM}}$ ). The fractions obtained were analyzed by SDS-PAGE, native agarose gel electrophoresis, and electron microscopy.

\section{3 | RESULTS}

\section{1 $\mathrm{CuMV}_{\mathrm{TT}}$-VLPs constitute an efficient platform for genetically fusing the receptor-binding motif (RBM)}

Our first attempt to generate a COVID-19 vaccine using CuMV VLPs platform, utilized eukaryotically expressed recombinant RBD which was chemically coupled to the VLPs using Succinimidyl 6-((beta-maleimidopropionamido)hexanoate) SMPH cross-linker ${ }^{21}$. This method resulted in a vaccine candidate that induced high levels of RBD-specific antibodies which were able to strongly inhibit RBD binding to ACE2 and neutralize SARS-CoV-2/ABS/NL20 virus ${ }^{22}$.

In an attempt to produce a more readily scalable vaccine candidate with better yields, we genetically fused RBM into $\mathrm{CuMV}_{\mathrm{TT}}$ 

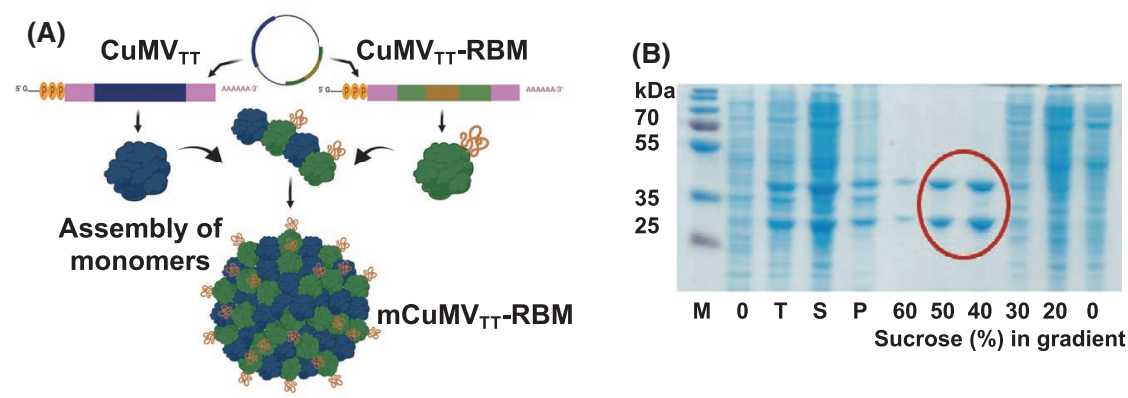

(C)

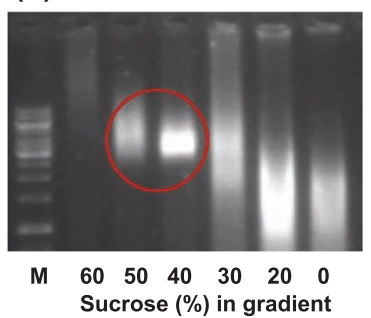

(D)

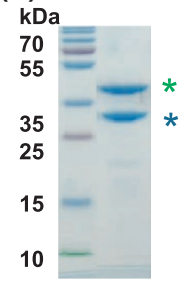

(E)

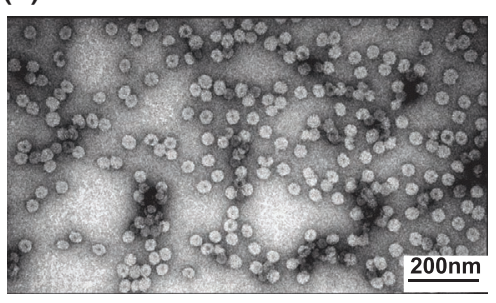

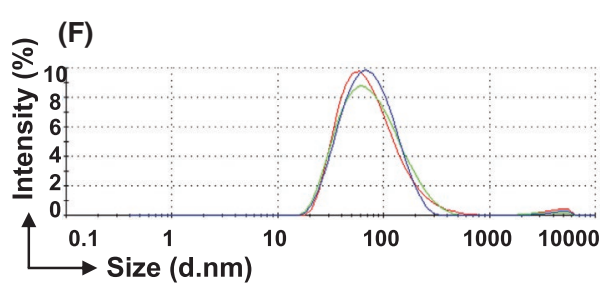

(G)

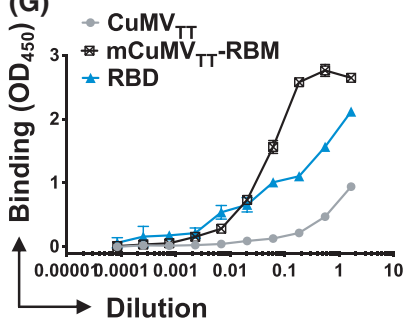

FIGURE $1 \mathrm{CUMV}_{\mathrm{TT}}$-VLPs constitute an efficient platform for genetically fusing the receptor-binding motif (RBM). A, Schematic depiction of $E$. coli cells containing pETDuet-1-derived plasmid, allowing the coexpression of $\mathrm{CuMV}_{\mathrm{TT}}-\mathrm{RBM}$ fusion and unmodified $\mathrm{CMV}_{\mathrm{TT}}$ genes and production of mosaic VLPs termed ( $\left.\mathrm{mCuMV}_{\mathrm{TT}}-\mathrm{RBM}\right), \mathrm{B}$, SDS-PAGE analysis of the production and sucrose gradient purification of $\mathrm{mCuMV}_{\mathrm{TT}}$-RBM. M-protein size marker (Thermo Scientific), 0 - total proteins in E.coli C2566 cells before IPTG induction; T-total proteins in E.coli C2566 cells after IPTG induction and $18 \mathrm{~h}$ cultivation at $20^{\circ} \mathrm{C} ; \mathrm{S}-$ soluble proteins in E.coli C2566 cells after induction and $18 \mathrm{~h}$ cultivation; $\mathrm{P}$-insoluble proteins in E.coli C2566 cells after induction and cultivation; 60 - 0 - sucrose gradient fractions after separation of cell lysate in Beckman SW32 rotor; $\mathrm{mCuMV}_{\mathrm{TT}}-\mathrm{RBM}$ VLP containing sucrose fractions are labeled with red circle; $\mathrm{C}$, native agarose gel analysis of the sucrose gradient fractions after sucrose gradient purification of $\mathrm{mCuMV}_{\mathrm{TT}}-\mathrm{RBM}$. M-DNA size marker (Thermo Scientific),

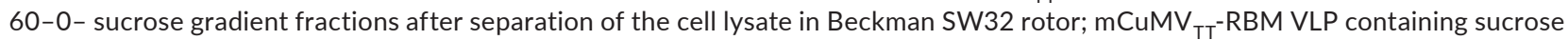
fractions are labeled with red circle; $\mathrm{D}, \mathrm{SDS}$-PAGE analysis of purified $\mathrm{mCuMV} \mathrm{TT}_{\mathrm{T}}-\mathrm{RBM}$ VLPs. M-protein size marker (Thermo Scientific), asterisk (blue) refers to unmodified $\mathrm{CuMV}_{\mathrm{TT}}$ monomer and asterisk (green) refers to genetically modified $\mathrm{CuMV}_{\mathrm{TT}}-\mathrm{RBM}_{\mathrm{E}}$, Electron

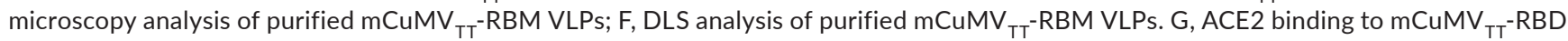
vaccine candidate, $\mathrm{CuMV}_{\mathrm{TT}}$, and RBD alone were used as controls. Plates coated with $1 \mu \mathrm{g} / \mathrm{ml}$ of ACE2. Binding was revealed using antiCuMV mAb. One representative of 2 similar experiments is shown

to produce a mosaic vaccine as illustrated in Figure $1 \mathrm{~A}$. The mosaic vaccine ( $\mathrm{mCuMV}_{\mathrm{TT}}-\mathrm{RBM}$ ) consists of both unmodified and a genetically modified monomer spontaneously assembling in E. coli to form VLPs. The genetically modified monomer displays RBM on the exterior VLP-surface. $\mathrm{mCuMV}_{\mathrm{TT}}-\mathrm{RBM}$ was expressed and produced in E. coli. Of note, incorporating either the whole RBD into a mosaic particle or modifying all VLP coat protein subunits with RBM was not successful and resulted in formation of coat protein aggregates and insoluble VLPs (data not shown). Purification of $\mathrm{mCuMV}_{\mathrm{TT}}-\mathrm{RBM}$ was carried out by ultracentrifugation using a $20-60 \%$ sucrose gradient (Figure 1B). We have shown previously that using E. coli as an expression system facilitates packaging of prokaryotic ssRNA which serves as a TLR7/8 ligand and results in enhanced immune responses in mice ${ }^{17,23}$ (Figure $1 C$ ). The final product $\mathrm{mCuMV}_{\mathrm{TT}}-\mathrm{RBM}$ consists of an unmodified VLP coat protein monomer of $28 \mathrm{kDA}$ in size while the genetically modified one is $\sim 42 \mathrm{kDA}$ as shown in the SDS-PAGE (Figure 1D). Densitometric analysis suggested 40-50\% incorporation of coat protein-RBM fusion molecules into the VLPs. As each VLP contains 180 capsid proteins, 40-50\% RBM incorporation means that each VLP has about 70-90 RBM antigens. Electron microscopy confirmed the successful assembly of icosahedral $\mathrm{mCuMV}_{\mathrm{TT}}-\mathrm{RBM}$ into $T=3$ particles with no sign of aggregation or malformation of particles (Figure 1E). Dynamic light scattering (DLS) revealed a uniform and homogenous peak of hydrodynamic diameter (DH) of $\sim 94 \mathrm{~nm}$ (Figure 1F). The observed larger size than seen by electron microscopy is due to water molecules surrounding the VLPs. 
FIGURE 2 mCuMV TT -RBM vaccine candidate shows high stability. A and $\mathrm{E}$, SDS-PAGE; $B$ and $F$, Agarose gel; $C$ and $\mathrm{G}$, DLS analysis of the $\mathrm{mCuMV}_{\mathrm{TT}}-\mathrm{RBM}$ vaccine, $\mathrm{D}$ and $\mathrm{H}$, Electron microscopy analysis of $\mathrm{mCuMV}_{\mathrm{TT}}$-RBM. Vaccine samples were analyzed directly after production and 14 month following storage at ${ }^{+} 4^{\circ} \mathrm{C}$. Asterisk in (blue), unmodified $\mathrm{CuMV}_{\mathrm{TT}}$ monomer; asterisk in (green), genetically modified $\mathrm{CuMV}_{\mathrm{TT}^{-}}$ RBM

$\mathrm{T}=0$

(A)

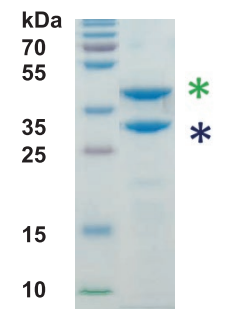

(B)

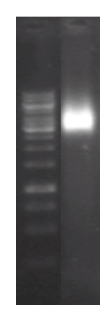

(C)

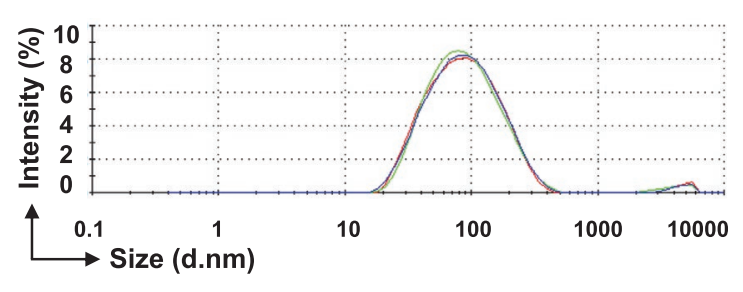

(D)

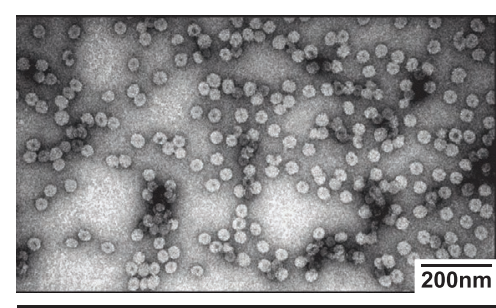

\section{$\mathrm{T}=14$ Months}

(E)

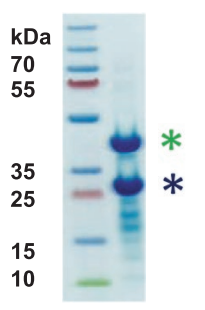

(F)

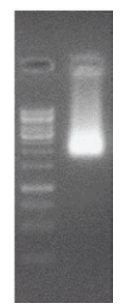

(G)

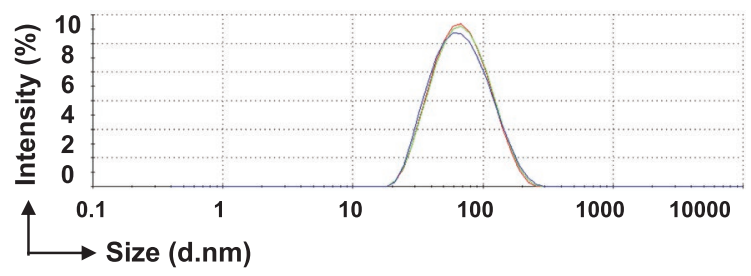

(H)

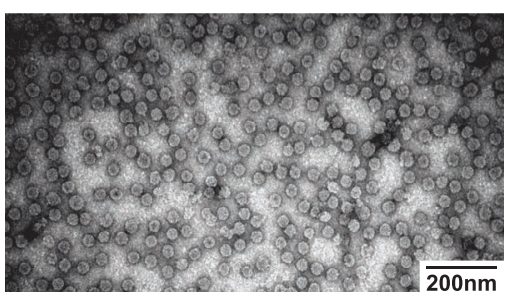

To confirm the native confirmation of RBM in the context of the mosaic fusion VLP, we tested whether the vaccine candidate was able to bind to ACE2. To this end, the human receptor ACE2 was coated onto an ELISA plate. The candidate vaccine $\mathrm{mCuMV}_{\mathrm{TT}}-\mathrm{RBM}$ or a control $\mathrm{CuMV}_{\mathrm{TT}}$ VLPs without an RBM insertion were then added followed by anti-CuMV $\mathrm{TT}_{\mathrm{TT}}$ secondary antibodies used to detect receptor bound VLPs. The results demonstrated that $\mathrm{mCuMV}_{\mathrm{TT}}-\mathrm{RBM}$ vaccine can bind to ACE2 receptor indicating that RBM exhibits the right native conformation(s) on the surface of the VLPs. The control did not show relevant binding (Figure 1G).

\section{2 $\mathrm{mCuMV} \mathrm{TT}_{\mathrm{TT}}-\mathrm{RBM}$ vaccine candidate shows high stability at $+4^{\circ} \mathrm{C}$}

Next, we tested the stability of $\mathrm{mCuMV}_{\mathrm{TT}}-\mathrm{RBM}$ after storage at $+4^{\circ} \mathrm{C}$ for 14 months. The stability of the vaccine was assessed and compared to a freshly produced vaccine by performing SDS-PAGE
(Figure $2 \mathrm{~A}$ and $\mathrm{E}$ ), agarose gel (Figure $2 \mathrm{~B}$ and $\mathrm{F}$ ), DLS analysis (Figure $2 \mathrm{C}$ and $\mathrm{G}$ ), and electron microscopy (Figure 2D and $\mathrm{H}$ ). The results indicated that the vaccine is highly stable for 14 months at $+4^{\circ} \mathrm{C}$ with no signs of degradation.

\section{3 $\mathrm{mCuMV} \mathrm{TT}^{-\mathrm{RBM}}$ induces high levels of specific antibodies with high avidity against RBD and spike protein of SARS-CoV-2}

We investigated the immunogenicity of the developed vaccine $\mathrm{mCuMV} \mathrm{TT}_{\mathrm{TT}}-\mathrm{RBM}$ in BALB/c mice using the s.c. vaccination route. We tested different doses and vaccination regimens as summarized in Table 1. The obtained results indicated that administering $100 \mu \mathrm{g}$ dose elicits the best immune response compared to other tested doses such as $5 \mu \mathrm{g}$ or $20 \mu \mathrm{g}$ (data not shown). Two vaccination regimens (Prime/Boost) have been compared; D0/D14 and D0/D28 as illustrated in Figure 3A. No adjuvants have been added as the vaccine 
(A)

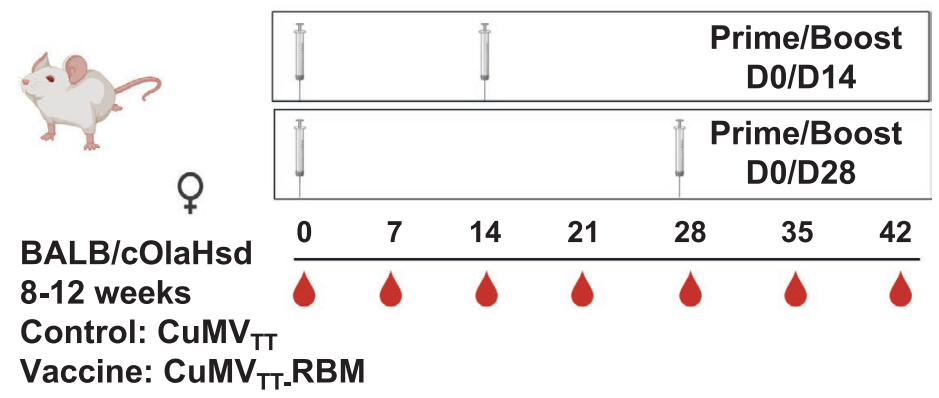

(C)

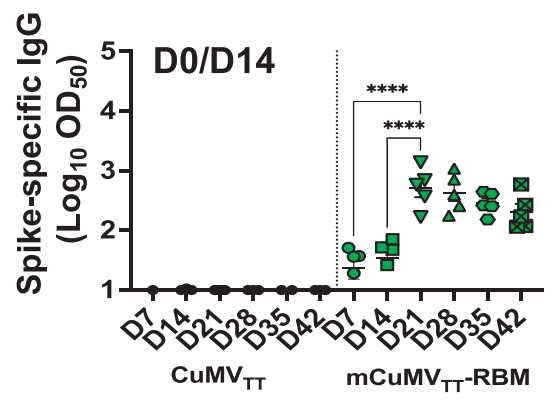

(E)
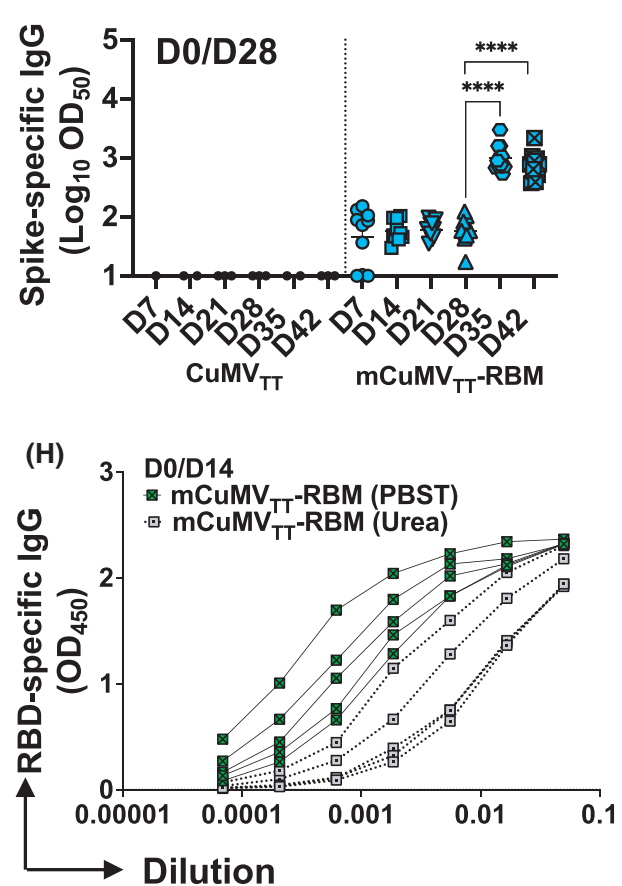

(J)

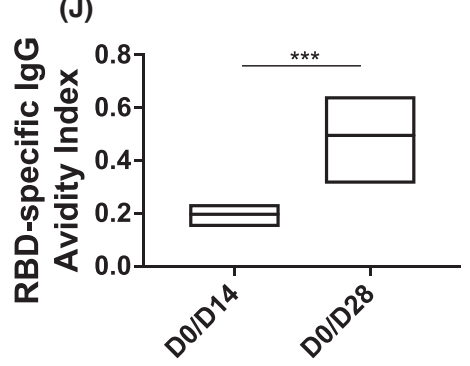

(F)

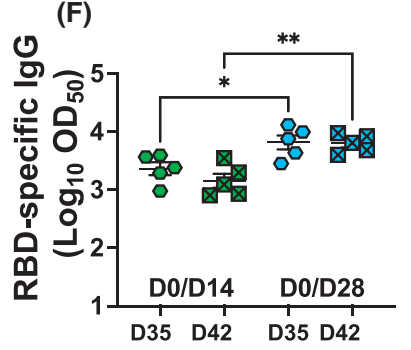

(B)

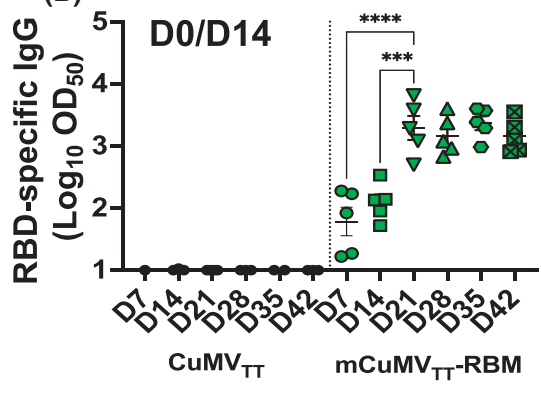

(D)

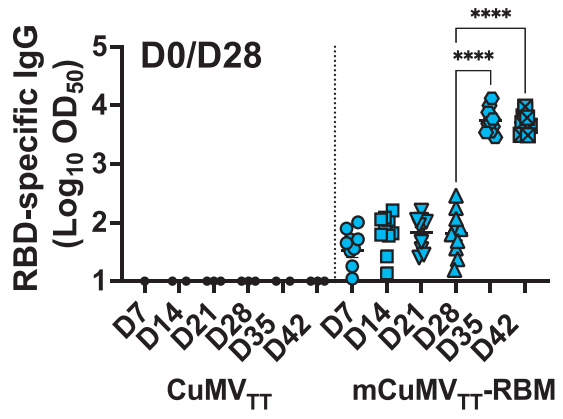

(G)

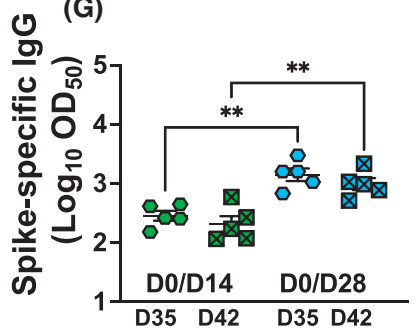

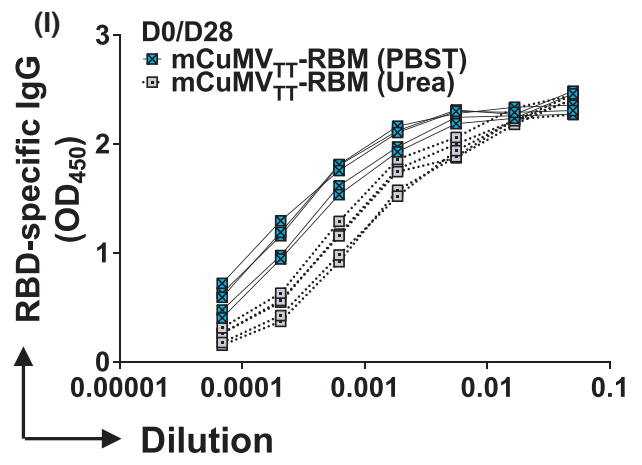

(K)

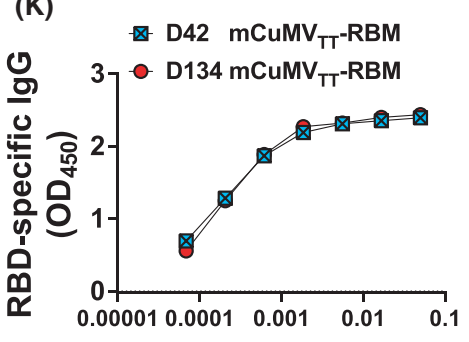

(L)

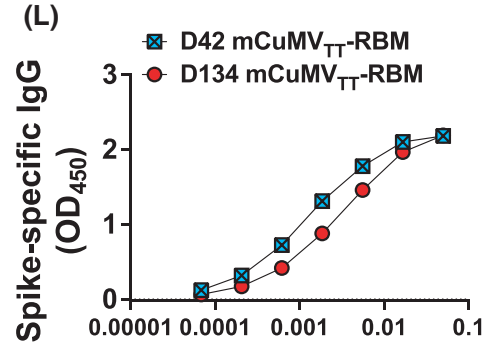


FIGURE $3 \quad \mathrm{mCuMV}_{\mathrm{TT}}$-RBM induces high levels of specific antibodies with high avidity against RBD and spike protein of SARS-CoV-2. A, Vaccination regimen (Prime/Boost) D0/D14 or D0/D28, bleeding schedule, and groups. B, $\log _{10} \mathrm{OD}_{50}$ of RBD-specific IgG titers for the groups vaccinated with $\mathrm{CuMV}_{\mathrm{TT}}$ as a control or $\mathrm{mCuMV}_{\mathrm{TT}}-\mathrm{RBM}$ on days 7, 14, 21, 28, 35, and 42 using D0/D14 regimen. C, $\mathrm{Log}_{10} \mathrm{OD}_{50}$ of

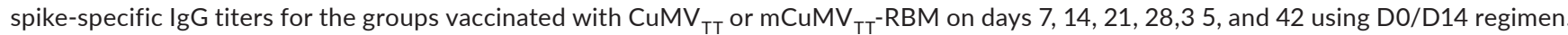

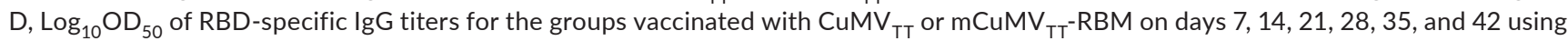
$\mathrm{D} 0 / \mathrm{D} 28$ regimen. $\mathrm{E}, \mathrm{Log}_{10} \mathrm{OD}_{50}$ of spike-specific IgG titers for the groups vaccinated with $\mathrm{CuMV}_{\mathrm{TT}}$ or $\mathrm{mCuMV}$ TT $-\mathrm{RBM}_{\text {on }}$ days $7,14,21$, 28,3 5, and 42 using D0/D28 regimen. F, Comparison between $\log _{10} \mathrm{OD}_{50}$ of RBD-specific IgG titers on days 35 and 42 using D0/D14 or D0/D28 regimens. G, Comparison between $\log _{10} \mathrm{OD}_{50}$ of spike-specific lgG titers on days 35 and 42 using D0/D14 or D0/D28 regimens. H, Avidity of RBD-specific IgG titers in mice vaccinated with $\mathrm{mCuMV}_{\mathrm{TT}}-\mathrm{RBM}_{\mathrm{T}}$ using D0/D14 regimen, sera were treated with PBST or $7 \mathrm{M}$ Urea. I, Avidity of spike-specific IgG titers in mice vaccinated with $\mathrm{mCuMV}_{\mathrm{TT}}-\mathrm{RBM}$ using D0/D14 regimen, sera were treated with PBST or $7 \mathrm{M}$ Urea. J, Avidity Index of RBD-specific IgG in mice vaccinated with $\mathrm{mCuMV}_{\mathrm{TT}}-\mathrm{RBM}_{\mathrm{C}} \mathrm{using} \mathrm{D0} / \mathrm{D} 14$ or D0/D28 regimens, sera were treated with PBST or $7 \mathrm{M}$ Urea. K, RBD-specific IgG titer for the group vaccinated with mCuMV $\mathrm{TT}^{-R B M}$ on days 42 and 134 . L, spike-specific IgG titer for the group vaccinated with $\mathrm{mCuMV}_{\mathrm{TT}}$-RBM on days 42 and 134. Statistical analysis (mean $\pm \mathrm{SEM}$ ) using one-way ANOVA in B-G or Student's t test in J, $\mathrm{n}=10$ or 5 . One representative of 3 similar experiments is shown. The value of $p<0.05$ was considered statistically significant $\left({ }^{*} p<0.01,{ }^{* *} p<0.001,{ }^{* * *} p<0.0001\right)$

is self-adjuvanted with the prokaryotic ssRNA packaged during the expression process ${ }^{15}$. The collected sera were tested for the induction of antibodies against RBD and spike protein of SARS-CoV-2. The results revealed a successful induction of anti-RBD IgGs as early as seven days following the priming dose using either regimens. The booster dose on day 14 or 28 augmented the response by approximately 10 -fold (Figure 3B and D). Antibody responses against the spike protein were also detected following the priming dose albeit to a lower extend, compared to RBD-specific responses. However, the response increased dramatically following the booster dose in both regimens (Figure $3 \mathrm{C}$ and $\mathrm{E}$ ).

When comparing the induced antibody titers following the booster dose for both regimens, D0/D28 regimen showed significantly higher RBD-specific antibodies on days 35 and 42 compared to D0/D14 regimen (p. 0.0409 and 0.0033, respectively) (Figure 3F). Such finding was also observed when comparing spike-specific antibodies (p. 0.0016 and 0.0021, respectively) (Figure 3G).

To assess the avidity of the induced antibodies, we performed a modified immunoassays using $7 \mathrm{M}$ urea to detach the low avidity antibodies. More specifically, we have compared the avidity of the RBD-specific antibodies in sera collected from day 42 in both regimens (D0/D14) and (D0/D28). The results revealed that $~ 50 \%$ of the induced RBD-specific antibodies are of high avidity when using D0/D28 vaccination regimen versus $20 \%$ only for D0/D14 regimen (p. 0.0008) (Figure 3H-J). Similar findings were seen for the induced spike-specific antibodies (p. 0.0144) (Figure S1).

It is also of interest to assess the longevity of antibodies induced after vaccination with $\mathrm{mCuMV}_{\mathrm{TT}}-\mathrm{RBM}$. Accordingly, we have tested RBD- and spike-specific IgG antibodies 134 days following priming. The results revealed that the antibody titers remained stable and remained comparable to the titers seen on day 42 (Figure $3 \mathrm{~K}$ and $\mathrm{L}$ ).

$\mathrm{mCuMV}_{\mathrm{TT}}-\mathrm{RBM}$ was also tested in rabbits (males and females) to evaluate the immunogenicity and potential toxicity (tolerability) of the vaccine candidate. Rabbits were vaccinated intramuscularly (i.m.) on day 0 and received booster doses on days 14 and 28. Sera collected on day 42 have shown a strong increase in RBD-specific antibodies (around $\mathrm{OD}_{50}$ of 1:10000) (Figure S2). Toxicological assessments demonstrated no evidence of clinical signs or systemic toxicity following multiple administrations of $\mathrm{mCuMV}_{\mathrm{TT}}-\mathrm{RBM}$ vaccine candidate. A mild influx of inflammatory cells at the injection site was observed.

\section{4 $\mathrm{mCuMV}_{\mathrm{TT}}-\mathrm{RBM}$ promotes IgA production and IgG responses are dominated by the IgG2a subclass}

Previous studies have shown that the different IgG subclasses play an essential role against viruses by complement fixation, enhancing opsonization, and immune effector function ${ }^{24}$. Accordingly, it is of interest to assess the IgG subclasses induced by the developed vaccine candidate. We therefore tested the vaccine for its ability to induce $\lg G 1$, IgG2a, IgG2b, and IgG3. The results indicated that $\mathrm{mCuMV}_{\mathrm{TT}}-\mathrm{RBM}$ induces the production of all four subclasses when binding is assessed on RBD protein as shown in Figure 4A and B. Analysis of $\log _{10} \mathrm{OD}_{50}$ showed a predominance of IgG2a. These results were confirmed when assessing the binding to the spike protein (Figure 4C and D).

Next, we tested the ability of $\mathrm{mCuMV}_{\mathrm{TT}}-\mathrm{RBM}$ to induce immunoglobulin class-switching to IgA using the two regimens D0/D14 and D0/D28. D0/D28 regimen induced higher RBD-specific IgA titers in comparison with D0/D14 regimen (Figure 4E). Determining the $\log _{10} \mathrm{OD}_{50}$ of IgA titers in both regimens confirmed the difference in antibody titers (Figure 4F).

\subsection{Sera of mice vaccinated with $\mathrm{mCuMV}_{\mathrm{TT}}-\mathrm{RBM}$ efficiently recognize SARS-CoV-2 variants of concern (VoC)}

We have previously produced a number of RBD variants, including the UK, Brazilian, and Indian $\mathrm{VoC}^{25,26}$, and have shown, as others, that mutations at position $\mathrm{E} 484 \mathrm{~K}$ strongly reduce recognition by convalescent sera ${ }^{26,27}$. It is therefore of significant interest that our vaccine induced immune sera recognized all VoC equally well as the wild type (Figure 5A and B). Hence, this vaccine candidate may have the potential to protect equally well against all $\mathrm{VoC}$ that have occurred up to now. 


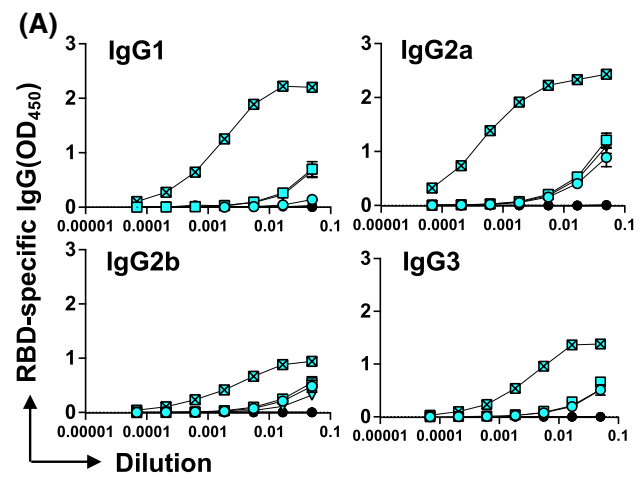

(C)

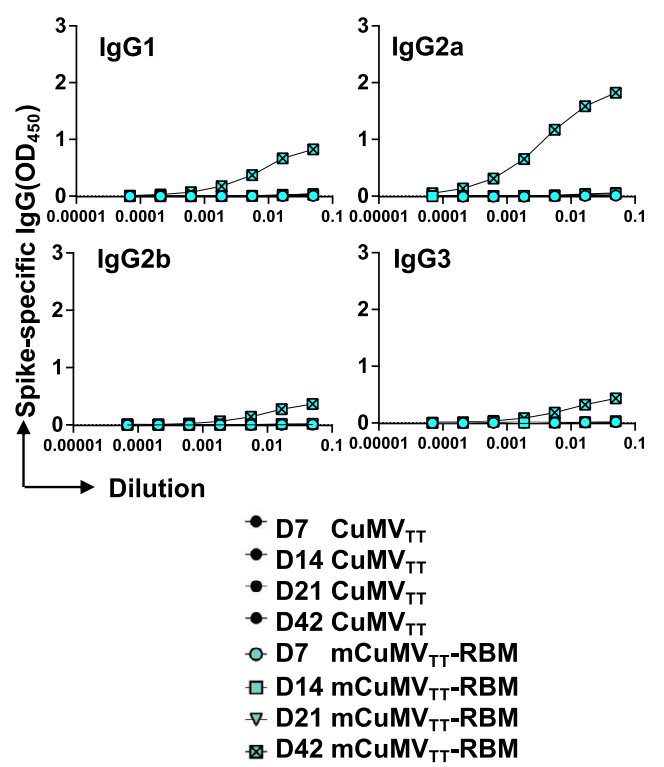

(E)

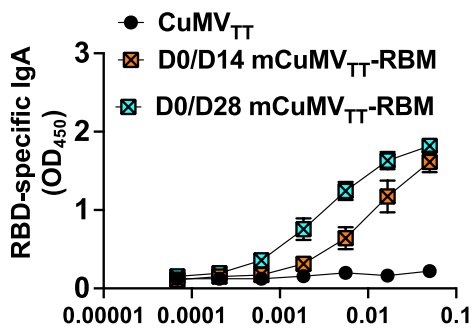

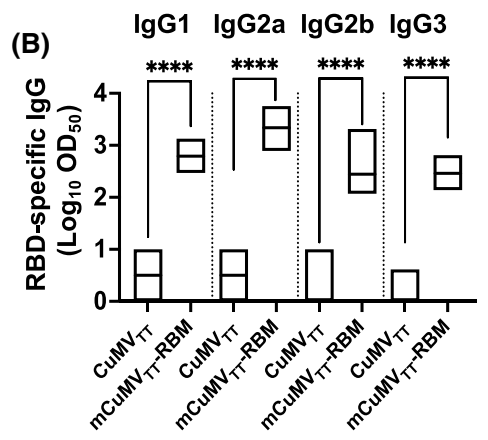

(D)
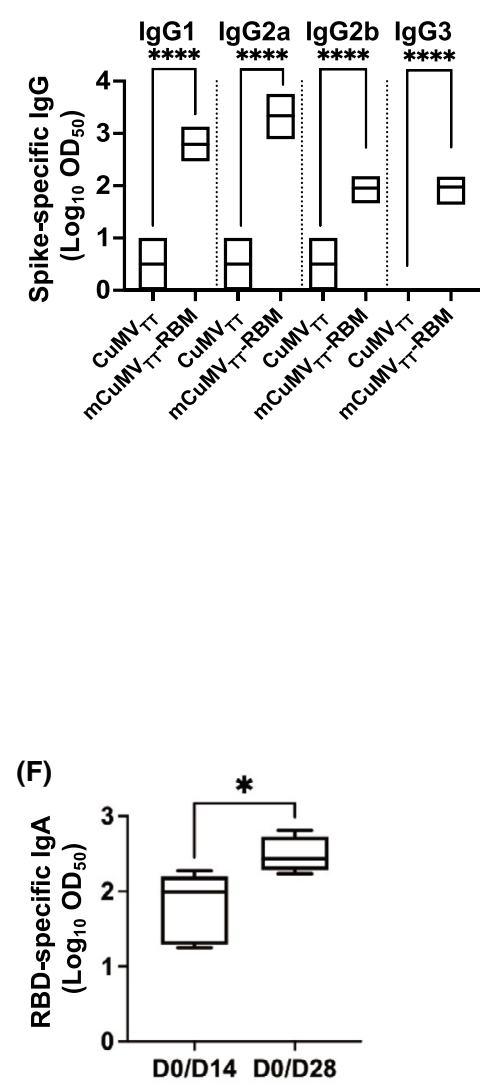

FIGURE 4 mCuMV $_{\mathrm{TT}}$-RBM promotes IgA production and IgG responses are dominated with IgG2a subclass. A, RBD-specific IgG titer for the groups vaccinated with $\mathrm{CuMV}_{\mathrm{TT}}$ as a control or $\mathrm{mCuMV}_{\mathrm{TT}}-\mathrm{RBM}$ on days $7,14,21$, and 42 measured by ELISA OD 450 . $B$, $\log _{10} \mathrm{OD}_{50}$ of RBD-specific IgG titers for the groups vaccinated with $\mathrm{CuMV}_{\mathrm{TT}}$ or $\mathrm{mCuMV}_{\mathrm{TT}}-\mathrm{RBM}$ on days 7, 14, 21 and 42 (Data from A). C, spike-specific IgG titers for the groups vaccinated with $\mathrm{CuMV}_{\mathrm{TT}}$ or $\mathrm{mCuMV} \mathrm{TT}_{\mathrm{TT}}-\mathrm{RBM}$ on days 7 , 14,21 , and 42 measured by ELISA OD 450 . $\mathrm{D}, \log _{10} \mathrm{OD}_{50}$ of spike-specific IgG titers for the groups vaccinated with $\mathrm{CuMV}_{\mathrm{TT}}$ or $\mathrm{mCuMV}_{\mathrm{TT}^{T}}$-RBM on days $7,14,21$, and 42 (Data from C). $\mathrm{CuMV}_{\mathrm{TT}} n=5$ and $m \mathrm{mCuMV}_{\mathrm{TT}}-\mathrm{RBM} n=10$. E, RBD-specific IgA titer for the groups vaccinated with $\mathrm{CuMV}_{\mathrm{TT}}$ or $\mathrm{mCuMV}_{\mathrm{TT}}-\mathrm{RBM}$ using D0/D14 or D0/D28 regimens, measured by ELISA $\mathrm{OD}_{450}$. F, $\log _{10} \mathrm{OD}_{50}$ of RBD-specific IgA titer for the groups vaccinated with $\mathrm{CuMV}_{\mathrm{TT}}$ or $\mathrm{mCuMV}_{\mathrm{TT}}-\mathrm{RBM}$ using D0/D14 or D0/D28 regimens, sera of day 35 was used. $\mathrm{CuMV}_{\mathrm{TT}} n=5$ and $\mathrm{mCuMV}_{\mathrm{TT}}-\mathrm{RBM}$ $n=5$. Statistical analysis (mean \pm SEM) using one-way ANOVA in B and D or Student's $t$ test in F. One representative of 3 similar experiments is shown. The value of $p<0.05$ was considered statistically significant $\left({ }^{*} p<0.01,{ }^{* *} p<0.001\right.$, $\left.{ }^{* * *} p<0.0001\right)$

\section{6 $\mathrm{mCuMV} \mathrm{TT}$-RBM induces higher} antibody titers in comparison with SARS-CoV-2 convalescent sera

In comparison with infections with other viruses, patients infected with COVID-19 produce neutralizing antibodies at relatively low levels ${ }^{28,29}$. Hence, we compared the total RBDspecific IgG titers induced in mouse sera after vaccination with $\mathrm{mCuMV}_{\mathrm{TT}}-\mathrm{RBM}$ to SARS-CoV-2 convalescent sera (total of 5 different sera). The results showed that the vaccine induces higher RBD-specific antibody titers even after a single priming dose compared to natural infection with SARS-CoV-2 and the booster injection further increased the RBD-specific antibody responses (Figure S3A and B). Analysis of Area Under Curve (AUC) indicated a strong difference $(p<0.0001)$ between mouse sera collected on day 14 (after priming) or day 42 (after boost) to convalescent sera (Figure S3C and D).

\subsection{Administration of a second booster dose further enhances antibody response and neutralization capacity of $\mathrm{mCuMV}_{\mathrm{TT}}-\mathrm{RBM}$}

In a next step, we compared the efficacy of vaccinating mice with a total of 2 doses of $\mathrm{mCuMV}_{\mathrm{TT}}-\mathrm{RBM}$ (Prime/Boost) versus 3 doses (Prime $/ 1^{\text {st }}$ Boost $/ 2^{\text {nd }}$ Boost) as illustrated in Figure $6 \mathrm{~A}$. The results showed no significant difference in the induced RBD-specific antibody titers following the $1^{\text {st }}$ boost in comparison with sera 
(A)

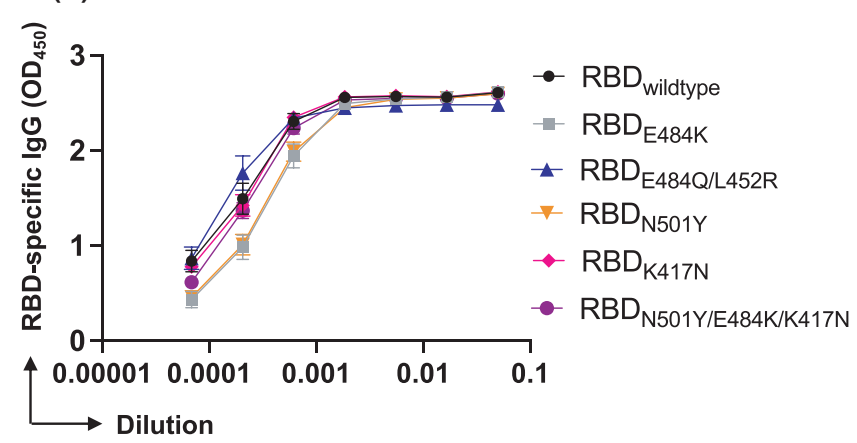

(B)

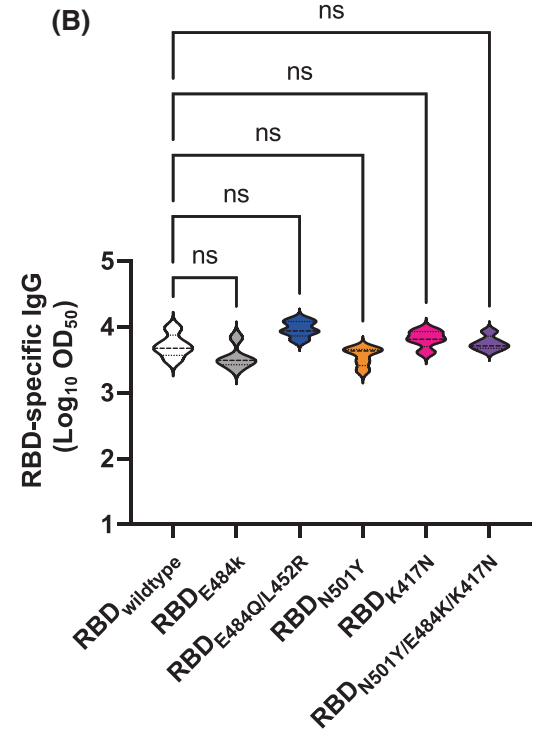

FIGURE 5 Sera of mice vaccinated with $m \mathrm{CUMV}_{\mathrm{TT}}$-RBM efficiently recognize SARS-CoV-2 Variants of Concern (VoC). A, RBD-specific IgG titers for the group vaccinated with $\mathrm{mCuMV}_{T^{-}}{ }^{-}$ RBM measured by ELISA OD 450 measured on day 42 . B, $\log _{10} \mathrm{OD}_{50}$ of RBD-specific IgG titers for the group vaccinated with $\mathrm{mCuMV}_{\mathrm{TT}^{-}}$ RBM (data from A). ELISA plates were coated with either $\mathrm{RBD}_{\text {wildtype }}, \mathrm{RBD}_{\mathrm{K} 417 \mathrm{~N}}, \mathrm{RBD}_{\mathrm{E} 484 \mathrm{~K}}, \mathrm{RBD}_{\mathrm{N} 501 \mathrm{Y}}, \mathrm{RBD}_{\mathrm{K} 417 \mathrm{~N} / \mathrm{E} 484 \mathrm{~K} / \mathrm{N} 501 \mathrm{Y} \text {, }}$ or $\mathrm{RBD}_{\mathrm{L} 452 \mathrm{R} / \mathrm{E} 484 \mathrm{Q}}$. Statistical analysis (mean $\pm \mathrm{SEM}$ ) using oneway ANOVA, $n=5$. One representative of 2 similar experiments is shown. The value of $p<0.05$ was considered statistically significant $\left({ }^{*} p<0.01,{ }^{* *} p<0.001,{ }^{* * *} p<0.0001\right)$

following the $2^{\text {nd }}$ boost (Figure 6B and C). Furthermore, the avidity of the induced antibodies after the $2^{\text {nd }}$ boost shows a slightly higher value when compared to the ones induced following the $1^{\text {st }}$ boost (Figure 6D and E) even though the difference did not reach statistical significance.

To test the capacity of the induced antibodies to neutralize the real virus, we have assessed reduction of cytopathic effect (CPE) using $100 \mathrm{TCID}_{50}$ of SARS-CoV-2/ABS/NL20. Titers are expressed as the highest dilution that inhibits formation of CPE by $100 \%$. A significant difference in neutralization capacity was seen when comparing sera of day 42 of vaccinated mice vs the control group $(p=0.0014)$. In addition, sera from mice after the $2^{\text {nd }}$ boost (day 63) further enhanced the neutralization titer when compared to the control group $(p .<0.00001)$ or the group received only 1 boost (p. 0.0021) (Figure 6F). The obtained results showed the capacity of the vaccine candidate to completely block the cytopathic effect of the virus.

\section{8 | Efficient upscaling of $\mathrm{mCuMV}_{\mathrm{TT}}$-VLPs vaccine candidate}

Manufacturability, in particular scalability and production yields are a critical attribute in selecting vaccines candidates to address a global pandemic. For this reason, we focused here on a VLP-based vaccine that can be efficiently produced in bacteria. Indeed, as the RBM of SARS-CoV- 2 is not glycosylated and has no other post-translational modifications, it may be an optimal candidate for a VLP-based vaccine candidate produced in E. coli.

Continuous flow ultracentrifugation is a method used to produce $>80 \%$ of the annual global influenza vaccine inventory which is approximately 1.5 billion doses ${ }^{30}$; continuous flow ultracentrifugation is thus an ideal and an established method for purification at large scale. To assess the potential yields of our production process, we produced a batch of $\mathrm{mCuMV}_{\mathrm{TT}}$-RBM in a 2-litre fermenter and purified the resultant VLPs by continuous flow ultracentrifugation (Figure S4). SDS-PAGE analysis showed good incorporation of RBM and EM-analysis showed well-formed particles (Figure S4B-D). The process yield from 2-litre fermentation volume was approximately $0.5 \mathrm{~g}$. This would correspond to 2.5 mio doses produced in a single 1000 -litre fermentation run. As this process is not optimized, there is the potential to significantly improve the already impressive yields.

\section{DISCUSSION}

In the current study, we investigated a novel VLP-based vaccine for COVID-19. Specifically, we have generated a mosaic VLP-vaccine using the plant-derived cucumber mosaic VLPs $\left(\mathrm{CuMV}_{T T}\right)$. Mosaic VLPs are well known in the field with GSKs RTS, $S$ malaria vaccines as the most prominent member in the field ${ }^{31,32}$. The mosaic vaccine candidate consists of an unmodified monomer and a genetically modified monomer that incorporates the RBM of SARS-CoV-2. The RBM was chosen as the target epitope due to the fact that RBD/ RBM are considered the immunological Achille's heel of SARS-CoV-2 and unlike RBD, RBM does not show any glycosylation, likely facilitating protein-protein interactions with ACE2 ${ }^{11,33,34}$. Furthermore, incorporating the whole RBD into $\mathrm{CuMV}_{\mathrm{TT}}$ did not allow the formation of VLPs most likely due to steric constraints. The used genetic fusion technique in this study facilitated the assembly of $T=3$ icosahedral mosaic VLPs which is essential for effective induction of a humoral immune response ${ }^{14}$. Using this technique, we have recently developed a vaccine against MERS-CoV by incorporating the RBM of MERS-CoV into $\mathrm{CuMV}_{\mathrm{TT}}$. The developed vaccine-induced antibodies that completely neutralized MERS-CoV/EMC/2012 isolate ${ }^{46}$. 
(A)

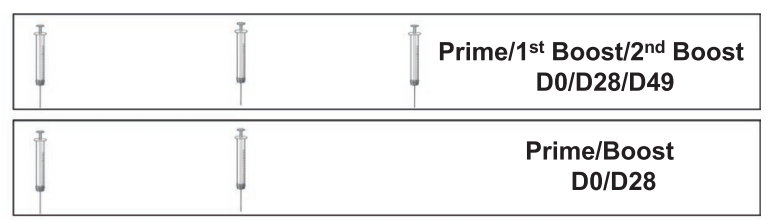

BALB/COlaHsd 8-12 weeks Control: $\mathrm{CuMV}_{\mathrm{T}}$ Vaccine: CuMV $_{\mathrm{TT}-\mathrm{RBM}}$
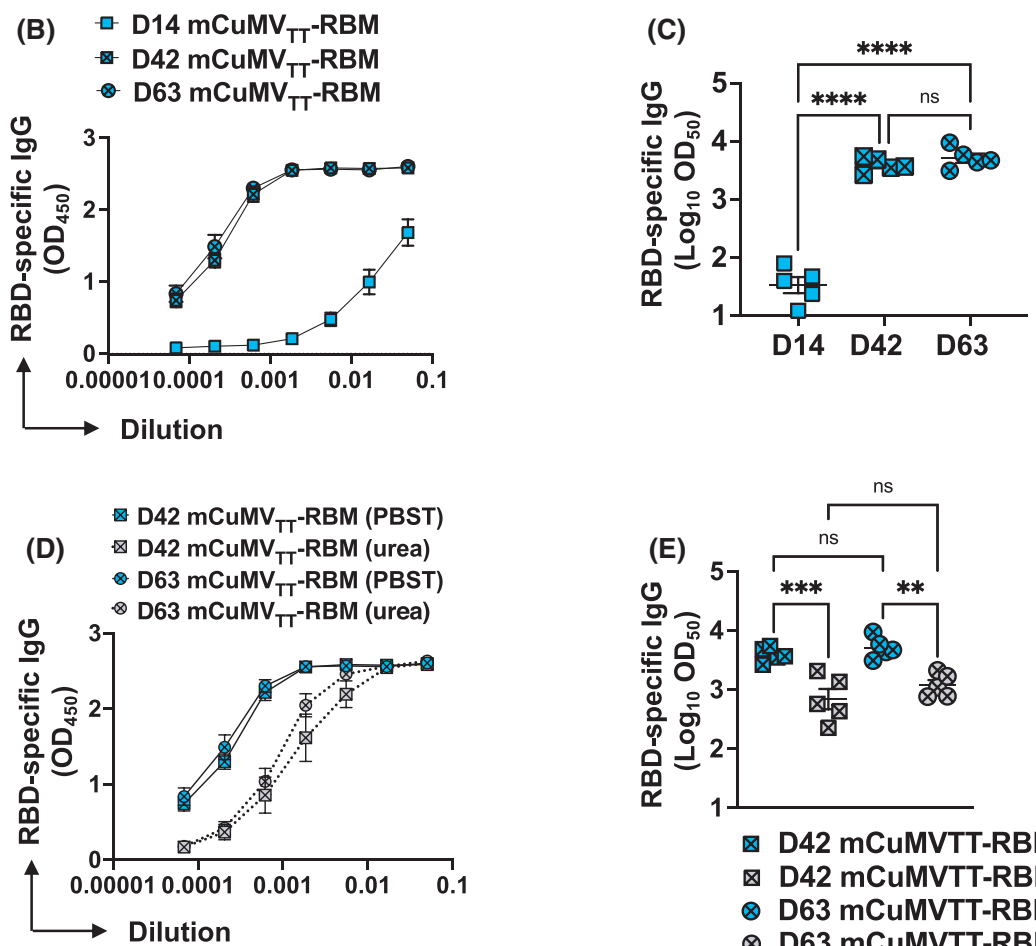

FIGURE 6 Administration of a second booster dose further enhances antibody response and neutralization capacity of $\mathrm{mCuMV}_{\mathrm{TT}}-\mathrm{RBM}$. A, Vaccination regimen D0/D28 or D0/D28/D49, bleeding schedule, and groups. B, RBD-specific IgG titers for the groups vaccinated with $\mathrm{mCuMV} \mathrm{TT}_{\mathrm{T}}-\mathrm{RBM}$ on day 14 (after prime), day 42 (after $1^{\text {st }}$ boost), and day 63 (after $2^{\text {nd }}$ boost) measured by ELISA OD ${ }_{450}$. $C$, $\log _{10} \mathrm{OD}_{50}$ of RBD-specific IgG titers for the groups vaccinated with $\mathrm{mCuMV}_{\mathrm{TT}^{-}}$ RBM on day 14 (after prime), day 42 (after $1^{\text {st }}$ boost), and day 63 (after $2^{\text {nd }}$ boost) (Data from B). D, Avidity of RBDspecific IgG titers in mice vaccinated with $\mathrm{mCuMV}_{\mathrm{TT}}$-RBM on day 42 (after $1^{\text {st }}$ boost) and day 63 (after $2^{\text {nd }}$ boost) measured by ELISA OD 450 , sera were treated with PBST or 7 M Urea. E, $\log _{10} \mathrm{OD}_{50}$ of RBDspecific IgG titers in mice vaccinated with $\mathrm{mCuMV}_{\mathrm{TT}}$-RBM on day 42 (after $1^{\text {st }}$ boost) and day 63 (after $2^{\text {nd }}$ boost) (data from $D$ ). $F$, Neutralization titer (CPE) for sera from mice vaccinated with $\mathrm{CuMV}_{\mathrm{TT}}$ as a control group, mice vaccinated with $\mathrm{mCuMV}_{\mathrm{TT}^{-}}$ RBM, sera from day 42 (after $1^{\text {st }}$ boost), and sera from day 63 (after $2^{\text {nd }}$ boost). Statistical analysis (mean \pm SEM) using Student's t test, $n=5$. One representative of 2 similar experiments is shown. The value of $p<0.05$ was considered statistically significant $\left({ }^{*} p<0.01,{ }^{* *} p<0.001\right.$, $\left.{ }^{* * *} p<0.0001\right)$

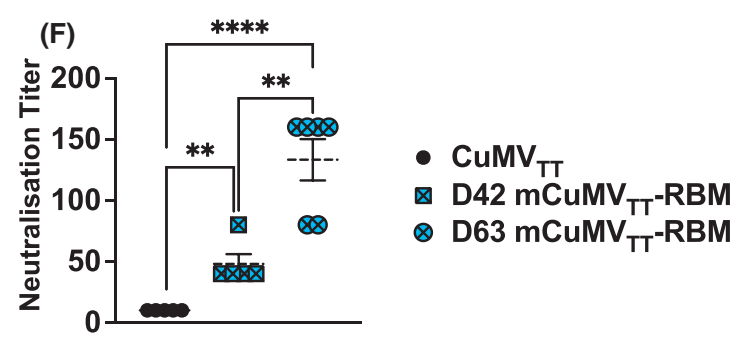

Furthermore, we have shown that fusing RBM into AP205-VLPs results in an effective vaccine candidate which induced RBD- and spike-specific antibodies which were capable of neutralizing the wild-type virus SARS-CoV-2/ABS/NL20 ${ }^{35}$. Development of AP205RBM vaccine required a refolding process which typically results in lower amounts of correctly folded target protein and may be distinguished from re-assembly processes used for HPV and hepatitis E virus (HEV) vaccines ${ }^{36}$. The simplicity of the downstream processing at industrial scale is therefore a major advantage of the current vaccine candidate.

Using $\mathrm{CuMV}_{\mathrm{TT}}$-VLPs as a vaccine platform, we were able to generate soluble mosaic VLPs. Densitometric analysis indicated $40-50 \%$ incorporation of RBM containing VLP subunits. Using Sandwich ELISAs, we have shown that $\mathrm{mCuMV}_{\mathrm{TT}}-\mathrm{RBM}$ vaccine candidate is able to detect and bind to the viral receptor ACE2. This confirms that the RBM displayed and fused to the VLP, has the correct conformation which is essential for the induction of the appropriate neutralizing antibody response. Expression in E. coli facilitates the packaging of bacterial RNA which serves as TLR7/8 ligand. We have shown previously that VLP-based vaccines are capable of inducing IL-21 independent secondary plasma cells only in the presence of TLR7/8 agonist such as bacterial ssRNA ${ }^{17,23}$. Additionally, TLR7/8 agonist polarizes the immune response toward $T_{H} 1$ and cytotoxic $T$ cells which is essential to avoid enhanced disease as shown in preclinical 
challenge models ${ }^{10}$. A recent study has shown that IgA antibodies in serum, saliva as well as bronchoalveolar lavage dominated the early response against SARS-CoV-2 infection in comparison with IgG and IgM. In addition, IgA serum antibodies were more potent at neutralizing wild-type SARS-CoV-2 than IgG ${ }^{37}$. We have previously shown that RNA-loaded VLPs may induce IgA responses, again in a TLR7/8 dependent manner ${ }^{17,38}$. This appears particularly important for SARS-CoV-2 and other respiratory disease-causing viruses, such as SARS-CoV and MERS-CoV-2, as IgA may be able to neutralize the virus locally in the lung without causing inflammation, a feature that may be particularly critical in patients with high viral load ${ }^{39}$. Thus, it is therefore of key importance that our newly developed vaccine candidate is able to induce a significant increase in serum IgA levels. Whether the increased serum IgA levels in mice can translate to correspondingly high IgA levels in humans, in particular at mucosal sites, needs to be established.

We have also shown that $\mathrm{mCuMV}_{\mathrm{TT}}$-RBM vaccine candidate induces high IgG responses in mice and rabbits. The response was further augmented following one booster dose. The avidity of an antibody is defined as the binding strength through points of interaction with the cognate antigen. It can be quantified as the ratio of the dissociation constant $K_{d}$ for the intrinsic affinity over the one for the functional affinity of an antibody ${ }^{40}$. Avidity and functional affinity terms can be exchanged in a looser sense ${ }^{41}$. Using an avidity ELISA, we observed that a D0/D28 vaccination regimen induced better quality of anti-RBD and spike antibodies in comparison with D0/D14 regimen. Furthermore, the addition of a $2^{\text {nd }}$ booster dose showed a slight increase in the avidity of the induced RBD-specific IgG avidity but was not statistically significant. This may indicate that it takes longer to induce such high-affinity/avidity antibodies at least in the case of $\mathrm{mCuMV}_{\mathrm{TT}}-\mathrm{RBM}$.

An ideal vaccine would have a long shelf life at ambient temperatures, nevertheless, many commercial vaccines require storage temperatures between ${ }^{+} 2-4^{\circ} \mathrm{C}^{42}$. While maintaining a vaccine in a cold chain below freezing temperature can be difficult in developed countries, it is particularly challenging and sometimes prohibitive for developing countries ${ }^{43}$. It is therefore an important feature of our vaccine candidate to show high stability for long periods at ${ }^{+} 4^{\circ} \mathrm{C}$.

Some studies have shown that neutralizing antibodies against SARS-CoV-2 are low in general and wane relatively rapidly ${ }^{44}$; some patients may even completely lack long-lasting SARS-CoV-2 antibodies ${ }^{28,29}$. This may be explained by coronaviruses morphological structure as they are large particles with long spike proteins resulting in RBD trimers spaced by $25 \mathrm{~nm}$. Other viruses and VLPs are capable of inducing optimal and long-lived neutralizing antibodies thanks to the 180 monomers forming a repetitive surface structure with epitopes spaced by $5-10 \mathrm{~nm}{ }^{28}$. The induced antibodies using $\mathrm{mCuMV}_{\mathrm{TT}}-\mathrm{RBM}$ vaccine could be detected at similar levels 3 months following the booster immunization, indicating longevity of the induced response.

The most important goal of any anti-viral vaccine is the induction of neutralizing antibodies that can inhibit SARS-CoV-2 infection. Our test sera were probed for their ability to inhibit a cytopathic effect of wildtype SARS-CoV-2 isolate on Vero cells. The induced antibodies have shown good neutralizing capability of the virus in particular following the $2^{\text {nd }}$ booster dose.

We have not directly measured the induction of $T_{H}$ cell responses by our vaccine candidate, mostly because the expected effector mechanism is induction of neutralizing antibodies. In addition, the size of the RBM may be too small to reliably induce a $T_{H}$ cell response in inbred mice. However, we have previously shown that VLP-specific $T_{H}$ cell responses mediate isotype-switch for $B$ cells specific for antigens displayed on the VLPs. Furthermore, the bacterial RNA packaged in VLPs, such as $\mathrm{CuMV}_{\mathrm{TT}}$, drive CD8, and $\mathrm{T}_{\mathrm{H}} 1$ responses 47,48 .

We and others have shown recently that N501Y mutation enhanced the binding affinity to ACE2 but did not significantly affect the recognition of RBD by convalescent sera. On the other hand, E484K mutation resulted in abolished recognition by convalescent sera ${ }^{45}$. $\mathrm{mCuMV}_{\mathrm{TT}}$-RBM is shown here to induce antibodies of much higher affinity/avidity than SARS-CoV-2 typically does in humans. This increased affinity/avidity translates to increased crossreactivity with SARS-CoV-2 VOC. Indeed, antibodies induced by the here presented vaccine candidate recognizes VoCs from Brazil, UK, and India with equal efficiency suggesting that our vaccine can protect against the new variants.

In addition to stability and high immunogenicity, production yields of $\mathrm{mCuMV}_{\mathrm{TT}}-\mathrm{RBM}$ are of key importance. Indeed, we were able to show in 2-litre bioreactor and continuous flow centrifugation that millions of doses may be produced in a single 1000-litre fermenter run. This is particularly important for less affluent countries, where affordability of vaccines is an important aspect.

Collectively, we have shown in this study that our novel mosaic VLP-based vaccine candidate can efficiently induce high levels of specific anti-RBD and spike antibodies that effectively neutralize SARSCoV-2 and highly cross-recognize all emerging viral VoC tested. As COVID-19 continues to represents a global threat to human health, it seems rational to further develop this vaccine candidate.

\section{ACKNOWLEDGMENT}

This work was supported by Saiba AG and Inselspital Bern. We thank PD Dr. AlexanderEggel and Dr. Daniel Brigger for providing wildtype RBD protein.

\section{CONFLICT OF INTEREST}

M. F. Bachmann is a board member of Saiba AG and holds the patent of CuMVTT-VLPs. G. T. Jennings and S. A. Walton work for Saiba AG. M. Mohsen and J. Sobczak received payments by Saiba AG to work on the development of a vaccine against Dengue Fever in the framework of a Eurostars grant. M. F. Bachmann, T. M. Kündig and M. O. Mohsen are shareholder of Saiba AG.

\section{AUTHORS' CONTRIBUTIONS}

MOM, MFB, AZ, IB, SZ, VZ, XL, XCPSK, KP, ZG, ASV, GA, MZ, SR, $\mathrm{DAR}, \mathrm{RJ}, \mathrm{KN}$ and $\mathrm{BM}$ : Design of experiments, acquisition of data, 
interpretation, and analysis of data. MOM, AZ, SMW, GTJ, MV, DES, and MFB: Writing, revision, and editing of manuscript. LAB, JMS, AN, JJC, DES, MV, MV, MOM, SMW, GTJ, AZ and MFB: Technical, material, and tool support. MOM, MV, SMW, GTJ, TK, AZ and MFB: Study supervision. All authors read and approved the final manuscript.

\section{ORCID}

Ina Balke (D) https://orcid.org/0000-0002-5171-7744

Simon Zinkhan (D) https://orcid.org/0000-0001-6023-6224

Xinyue Chang (D) https://orcid.org/0000-0001-7027-3889

Gilles Augusto (D) https://orcid.org/0000-0001-6509-0148

Monique Vogel (D) https://orcid.org/0000-0002-5219-4033

Martin F. Bachmann (D) https://orcid.org/0000-0003-4370-2099

\section{REFERENCES}

1. Guan WJ, Ni ZY, Hu Y, et al. Clinical Characteristics of Coronavirus Disease 2019 in China. N Engl J Med. 2020.

2. Amirfakhryan H, Safari F. Outbreak of SARS-CoV2: Pathogenesis of infection and cardiovascular involvement. Hellenic J Cardiol. 2021;62(1):13-23.

3. Petrosillo N, Viceconte G, Ergonul O, Ippolito G, Petersen E. COVID-19, SARS and MERS: are they closely related? Clin Microbiol Infect. 2020;26(6):729-734.

4. Awadasseid A, Wu Y, Tanaka Y, Zhang W. Current advances in the development of SARS-CoV-2 vaccines. Int J Biol Sci. 2021;17(1):8-19.

5. Cevik M, Kuppalli K, Kindrachuk J, Peiris M. Virology, transmission, and pathogenesis of SARS-CoV-2. BMJ. 2020;371:m3862.

6. Phan T. Novel coronavirus: From discovery to clinical diagnostics. Infect Genet Evol. 2020;79:104211.

7. Bhat EA, Khan J, Sajjad N, et al. SARS-CoV-2: Insight in genome structure, pathogenesis and viral receptor binding analysis - An updated review. Int Immunopharmacol. 2021;95107493.

8. Hoffmann M, Kleine-Weber H, Schroeder S, et al. SARS-CoV-2 Cell Entry Depends on ACE2 and TMPRSS2 and Is Blocked by a Clinically Proven Protease Inhibitor. Cell. 2020;181(2):271-80 e8.

9. Lan J, Ge J, Yu J, et al. Structure of the SARS-CoV-2 spike receptor-binding domain bound to the ACE2 receptor. Nature 2020;581(7807):215-220.

10. Speiser DE, Bachmann MF. COVID-19: Mechanisms of Vaccination and Immunity. Vaccines (Basel). 2020;8(3):404

11. Casalino L, Gaieb Z, Goldsmith JA, et al. Beyond Shielding: The Roles of Glycans in the SARS-CoV-2 Spike Protein. ACS Cent Sci. 2020;6(10):1722-1734.

12. Lane TF, Eber RM, Gansky S, Reddy MS. Vaccines for COVID-19: An Overview. Compend Contin Educ Dent. 2021;42(6):298-304. quiz 5.

13. Malik JA, Mulla AH, Farooqi T, Pottoo FH, Anwar S, Rengasamy KRR. Targets and strategies for vaccine development against SARSCoV-2. Biomed Pharmacother. 2021;137:111254.

14. Zinkhan S, Ogrina A, Balke I, et al. The impact of size on particle drainage dynamics and antibody response. J Control Release. 2021;331:296-308.

15. Mohsen MO, Augusto G, Bachmann MF. The 3Ds in virus-like particle based-vaccines: "Design, Delivery and Dynamics". Immunol Rev. 2020;296:155-168.

16. Zeltins A, West J, Zabel F, et al. Incorporation of tetanus-epitope into virus-like particles achieves vaccine responses even in older recipients in models of psoriasis, Alzheimer's and cat allergy. NPJ Vaccines. 2017;2:30.

17. Bessa J, Kopf M, Bachmann MF. Cutting edge: IL-21 and TLR signaling regulate germinal center responses in a B cell-intrinsic manner. J Immunol. 2010;184(9):4615-4619.
18. Bachmann MF, Zeltins A, Kalnins G, et al. Vaccination against IL-31 for the treatment of atopic dermatitis in dogs. J Allergy Clin Immunol. 2018;142(1):279-81 e1.

19. Fettelschoss-Gabriel A, Fettelschoss V, Thoms F, et al. Treating insect-bite hypersensitivity in horses with active vaccination against IL-5. J Allergy Clin Immunol. 2018;142(4):1194-205 e3.

20. Brigger D, Horn MP, Pennington LF, et al. Accuracy of serological testing for SARS-CoV-2 antibodies: First results of a large mixedmethod evaluation study. Allergy. 2021;76(3):853-865.

21. Zha L, Hongxin Z, Mohsen MO, et al. Development of a vaccine against the newly emerging COVID-19 virus based on the receptor binding domain displayed on virus-like particles. BioRxiv. 2020.

22. Zha L, Chang X, Zhao H, et al. Development of a Vaccine against SARS-CoV-2 Based on the Receptor-Binding Domain Displayed on Virus-Like Particles. Vaccines (Basel). 2021;9(4):395.

23. Krueger CC, Thoms F, Keller E, Leoratti FMS, Vogel M, Bachmann MF. RNA and Toll-Like Receptor 7 License the Generation of Superior Secondary Plasma Cells at Multiple Levels in a B Cell Intrinsic Fashion. Front Immunol. 2019;10:736.

24. Hazenbos WL, Heijnen IA, Meyer D, et al. Murine IgG1 complexes trigger immune effector functions predominantly via Fc gamma RIII (CD16). J Immunol. 1998;161(6):3026-3032.

25. Canton R, De Lucas RP, Garcia-Botella A, et al. New variants of SARS-CoV-2. Rev Esp Quimioter. 2021;34(5):419-428.

26. Chang X, Augusto GS, Liu X, et al. BNT162b2 mRNA COVID-19 vaccine induces antibodies of broader cross-reactivity than natural infection, but recognition of mutant viruses is up to 10 -fold reduced. Allergy. 2021;76(9):2895-2998. https://doi.org/10.1111/all.14893

27. Harvey WT, Carabelli AM, Jackson B, et al. SARS-CoV-2 variants, spike mutations and immune escape. Nat Rev Microbiol. 2021;19(7):409-424. 10.1038/s41579-021-00573-0

28. Breuer A, Raphael A, Stern H, Odeh M, Fiszlinski J, Algur N, Magen S, Megged O, Schlesinger Y, Barak-Corren Y, Heiman E. SARS-CoV-2 antibodies started to decline just four months after COVID-19 infection in a paediatric population. Acta Paediatrica. 2021;http://dx. doi.org/10.1111/apa.16031

29. Bosnjak B, Stein SC, Willenzon S, et al. Low serum neutralizing antiSARS-CoV-2 $S$ antibody levels in mildly affected COVID-19 convalescent patients revealed by two different detection methods. Cell Mol Immunol. 2021;18(4):936-944.

30. Sparrow E, Wood JG, Chadwick C, et al. Global production capacity of seasonal and pandemic influenza vaccines in 2019. Vaccine. 2021;39(3):512-520.

31. Rts SCTP. Efficacy and safety of RTS, S/AS01 malaria vaccine with or without a booster dose in infants and children in Africa: final results of a phase 3 , individually randomised, controlled trial. Lancet. 2015;386(9988):31-45.

32. Collins KA, Snaith R, Cottingham MG, Gilbert SC, Hill AVS. Enhancing protective immunity to malaria with a highly immunogenic virus-like particle vaccine. Sci Rep. 2017;7:46621.

33. Bachmann MF, Mohsen MO, Zha LS, Vogel M, Speiser DE. SARSCoV-2 structural features may explain limited neutralizing-antibody responses. Npj Vaccines. 2021;6(1):2.

34. Huang $\mathrm{Y}$, Yang C, Xu XF, Xu W, Liu SW. Structural and functional properties of SARS-CoV-2 spike protein: potential antivirus drug development for COVID-19. Acta Pharmacol Sin. 2020;41(9):1141-1149.

35. Liu X, Chang X, Rothen D, etal. AP205 VLPs Based on Dimerized Capsid Proteins Accommodate RBM Domain of SARS-CoV-2 and Serve as an Attractive Vaccine Candidate. Vaccines (Basel). 2021;9(4):403.

36. Balke I, Zeltins A. Use of plant viruses and virus-like particles for the creation of novel vaccines. Adv Drug Deliver Rev. 2019;145:119-129.

37. Sterlin D, Mathian A, Miyara M, et al. IgA dominates the early neutralizing antibody response to SARS-CoV-2. Sci Transl Med. 2021;13(577):eabd2223. 
38. Bessa J, Zabel F, Link A, et al. Low-affinity B cells transport viral particles from the lung to the spleen to initiate antibody responses. Proc Natl Acad Sci U S A. 2012;109(50):20566-20571.

39. Rodriguez A, Tjarnlund A, Ivanji J, et al. Role of IgA in the defense against respiratory infections IgA deficient mice exhibited increased susceptibility to intranasal infection with Mycobacterium bovis BCG. Vaccine. 2005;23(20):2565-2572.

40. Polack FP, Hoffman SJ, Crujeiras G, Griffin DE. A role for nonprotective complement-fixing antibodies with low avidity for measles virus in atypical measles. Nat Med. 2003;9(9):1209-1213.

41. Klasse PJ. How to assess the binding strength of antibodies elicited by vaccination against HIV and other viruses. Expert Review of Vaccines. 2016;15(3):295-311.

42. Organization WH. Temperature sensitivity of vaccines 2006. [Available from: https://apps.who.int/iris/handle/10665/69387

43. Wang J, Peng Y, Xu H, Cui Z, Williams RO 3rd. The COVID-19 Vaccine Race: Challenges and Opportunities in Vaccine Formulation. AAPS PharmSciTech. 2020;21(6):225.

44. Tay MZ, Poh CM, Renia L, MacAry PA, Ng LFP. The trinity of COVID-19: immunity, inflammation and intervention. Nat Rev Immunol. 2020;20(6):363-374.

45. Vogel M, Augusto GS, Chang X, et al. Molecular definition of SARSCoV-2 RBD mutations: receptor affinity versus neutralization of receptor interaction. Allergy. 2021.

46. Mohsen MO, Rothen D, Balke I, Martina B, Zeltina V, Inchakalody V, Gharailoo Z, Nasrallah G, Dermime S, Tars K, Vogel M, Zeltins A, Bachmann MF. Neutralization of MERS coronavirus through a scalable nanoparticle vaccine. npj Vaccines. 2021;6(1):http://dx.doi. org/10.1038/s41541-021-00365-w

47. Donaldson B, Lateef Z, Walker GF, Young SL, Ward VK. Virus-like particle vaccines: immunology and formulation for clinical translation. Expert Review of Vaccines. 2018;17(9):833-849. http://dx.doi. org/10.1080/14760584.2018.1516552

48. Skibinski DAG, Hanson BJ, Lin Y, von Messling V, Jegerlehner A, Tee JBS, Chye DH, Wong SKK, Ng AAP, Lee HY, Au B, Lee BTK, Santoso L, Poidinger M, Fairhurst A-M, Matter A, Bachmann MF, Saudan P, Connolly JE. Enhanced Neutralizing Antibody Titers and Th1 Polarization from a Novel Escherichia coli Derived Pandemic Influenza Vaccine. PLoS ONE. 2013;8(10):e76571. http://dx.doi. org/10.1371/journal.pone.0076571

\section{SUPPORTING INFORMATION}

Additional supporting information may be found in the online version of the article at the publisher's website.

How to cite this article: Mohsen MO, Balke I, Zinkhan S, et al. A scalable and highly immunogenic virus-like particle-based vaccine against SARS-CoV-2. Allergy. 2022;77:243-257. https://doi.org/10.1111/all.15080 